\title{
A Tertiary Review on Blockchain and Sustainability with Focus on Sustainable Development Goals
}

This paper was downloaded from TechRxiv (https://www.techrxiv.org).

\section{LICENSE}

CC BY 4.0

SUBMISSION DATE / POSTED DATE

$15-01-2022$ / 20-01-2022

\section{CITATION}

Jiang, Shanshan; Jakobsen, Kine; Bueie, Jonas; Li, Jingyue; Haro, Peter Halland (2022): A Tertiary Review on Blockchain and Sustainability with Focus on Sustainable Development Goals. TechRxiv. Preprint. https://doi.org/10.36227/techrxiv.18480509.v1

$\mathrm{DOI}$

10.36227/techrxiv.18480509.v1 


\title{
A Tertiary Review on Blockchain and Sustainability with Focus on Sustainable Development Goals
}

\author{
Shanshan Jiang ${ }^{1}$, Kine Jakobsen ${ }^{2}$, Jonas Bueie ${ }^{3}$, Jingyue $\mathrm{Li}^{3}$, and Peter Halland Haro ${ }^{2}$ \\ ${ }^{1}$ SINTEF Digital, P.O. Box 4760 Torgarden, 7465 Trondheim, Norway \\ ${ }^{2}$ SINTEF Nord, Storgata 118, 9008 Tromsø, Norway \\ ${ }^{3}$ Department of Computer Science, Norwegian University of Science and Technology, 7419 Trondheim, Norway \\ Corresponding author: Shanshan Jiang (e-mail: shanshan.jiang@sintef.no).
}

This work was jointly supported by the National Key Research and Development Program of China (No. 2019YFE0105500), the Research Council of Norway (No. 309494 and 274816) and the Norwegian Regional Research Fund Nord (No. 299423).

\begin{abstract}
Blockchain as a disruptive technology and a driver for social changes has been applied to a wide range of applications, exhibiting a great potential to promote sustainable practices and help organizations and governments to achieve United Nations' Sustainable Development Goals (SDG). Literature reviews on blockchain and sustainability exist, but there is a need to consolidate existing results in terms of SDGs. This paper presents a tertiary review based on 28 existing literature reviews to investigate the relationship between blockchain and sustainability, focusing on SDGs. The findings include a novel mapping of impact-based interlinkage of blockchain and SDGs and a systematic overview of drivers and barriers to adopting blockchain for sustainability. Research gaps to overcome the barriers and enhance blockchain's positive impacts on SDGs are identified. We found that blockchain applications are still in their early stages. Future empirical studies are needed regarding their large-scale deployment and long-term impacts on sustainability as well as standard tools and methods for implementing blockchain-based sustainable solutions from the software engineering perspective.
\end{abstract}

INDEX TERMS Blockchain, Sustainability, Sustainable Development Goals, Tertiary review 


\section{INTRODUCTION}

Sustainability is receiving growing attention and commitments worldwide. The United Nations' 2030 agenda for sustainable development has established 17 Sustainable Development Goals (SDGs) and 169 targets associated with the SDGs [1]. Recently, studies on SDGs and their indicators have gained momentum. There have been many sustainable development initiatives to improve sustainability by integrating emerging technologies such as artificial intelligence, Internet of Things (IoT), big data, and blockchain.

Blockchain is a decentralized information technology building on immutable, shared, distributed ledgers to store transactions and establish trust [2]. The benefits of blockchain include decentralization without central authorities, better information traceability, better data transparency and better security than classical technologies. Although blockchain is still a rapidly evolving technology, it drives social changes in many domains, expanding from the original application domain of finance [3] to smart cities [4], supply chain and logistics [5], energy [6], smart manufacturing and industry 4.0 [7], healthcare [2], maritime transport [8], and others.

There is increasing research on applying blockchain technology to address sustainability. Blockchain-based applications are "tracking potential social and environmental conditions that might pose environmental, health, and safety concerns" [5]. Supply chain traceability has a significant role in contributing to SDGs, particularly SDGs 8, 9, and 12 [9][10]. Applying blockchain technology to improve traceability for sustainability has been recognized and explored [11][12]. Blockchain makes it possible to verify sustainability with meaningful and quantifiable indicators [13]. For example, blockchain traceability can help measure the carbon footprint of products from a specific company and calculate the corresponding carbon tax [5].

Literature has reported blockchain's positive and negative impacts on sustainability. An example of positive impacts is that blockchain traceability can help discover unethical suppliers and counterfeit products and better ensure human rights and fair working practices [5]. On the other hand, the Proof-of-Work consensus algorithms are often considered not environmentally friendly due to their high energy consumption [13]. Getting a complete picture of the impacts of blockchain technology and applications on sustainability can help people take advantage of blockchain technologies and address drawbacks. There are studies reporting blockchain for the sustainable development of specific application domains, industries, or aspects [6][8][13][14][15][16]. However, there is no holistic analysis of blockchain's impacts on sustainability across domains or areas, particularly SDGs. The goal of our study is to investigate how does blockchain technology contribute to sustainable development related to different SDGs? Besides analyzing the impacts, we also want to know the reasons for the impacts and the research gaps to enlarge blockchain's positive impacts and limit the negative ones. In detail, we aim to answer the following research questions (RQs):

- RQ1: What are the positive and negative impacts on SDGs by using blockchain technology in various applications?

- RQ2: What are the key drivers and barriers to adopting blockchain technology to satisfy SDG goals?

- RQ3: What are the research gaps to facilitate sustainability using blockchain technology?

Several reviews, e.g., [4][6][13][14][16], exist on this topic from different aspects. So, we decided to perform a tertiary review to answer our research questions [17]. A tertiary review, or a tertiary study, is "a review of secondary studies related to the same research questions" [18], i.e., a review of systematic literature reviews. We used thematic analysis methods [19] to extract information from existing reviews to answer our research questions. We have analyzed and consolidated information from 28 review articles, of which 22 were published since 2019. The main contributions of this study are:

- We have identified 73 positive and 10 negative linkages between blockchain-based applications and each of the 17 SDGs through a holistic and systematic analysis of the blockchain's impacts on SDGs.

- We have identified 45 factors that drive or hinder the adoption of blockchain technologies to satisfy SDGs. We have classified the factors into four categories: intraorganizational, inter-organizational, technical and system-related, and external.

- We have also recognized 8 research gaps and directions to motivate further development of blockchain technology to promote SDGs.

The remainder of the paper is organized as follows: Section II provides background information related to sustainability and the critical features of blockchain. Section III describes the methodology of the study. The findings of this study are presented in Section IV. Section V discusses the results. Finally, Section VI concludes the paper and proposes future work.

\section{BACKGROUND}

\section{A. SUSTAINABILITY AND SUSTAINABLE DEVELOPMENT GOALS}

Sustainability is an essential concept with many definitions. The triple-bottom-line proposed by Elkington is a widely accepted concept that assesses sustainability from the economic, environmental, and social dimensions [20]. Urban sustainability has defined four dimensions, i.e., social, economic, environmental, and governmental [16].

In 1987, the United Nations Brundtland Commission defined sustainability as meeting "the needs of the present without compromising the ability of future generations to meet their own needs" [21]. The United Nations adopted the 
Sustainable Development Goals (SDGs) in 2015 as a call for action by all countries to end poverty, fight inequality, protect the planet, and ensure peace and prosperity for all people by 2030. The 17 SDGs are interrelated, in the sense that "action in one area will affect outcomes in others, and that development must balance social, economic and environmental sustainability" [22]. The SDGs reflect transnational recognition of the need for a developing model assuring life quality and habitable earth for both this and future generations. That is, acknowledging the need for an agreement regulating interest conflicts.

The SDGs are meant to function as a global framework for cooperation to address economic development, social inclusion, and environmental sustainability. Achieving the SDGs requires transnational, multi-stakeholder collaboration, holding an imperative for stakeholders to act according to collective rationality, thus potentially renunciate intra- and inter-state interests for the common good. However, there is a strong reservation as to whether this is feasible, and it has proved challenging to get all parties adequately involved and anchored. A recent example is the United States', albeit temporary, withdrawal from the Paris Agreement. This example showcases the imminent risk in political constellations associated with, e.g., replacement of administrations or individuals, resulting in shifting or even termination of interests or consensus, constituting an inherent lack of predictability and trust.

\section{B. BLOCKCHAIN TECHNOLOGY AND BLOCKCHAIN- \\ BASED APPLICATIONS}

Blockchain technology comprises a multitude of underlying technologies and protocols, which is referred to as "blockchain technology" (BCT) or simply "blockchain" in this paper. A blockchain is a decentralized digital ledger that provides transparency and immutability of encrypted records or digital events. A blockchain records every transaction on a block across multiple copies of the ledger shared with many parties without the need of intermediaries or centralized control, where everyone has access to the data (transparency). The data is stored with a unique identifier, a cryptographically secure hash, which depends on the data stored in the last and previous blocks [23]. The hash acts as the main guarantee for data integrity in the blockchain, and "a change in a single block in the blockchain results in invalidating all the following blocks" [6]. The security is enhanced by verifying transactions via multiple nodes in the blockchain through a consensus algorithm before a block is added to the blockchains. There exist several consensus algorithms, such as Proof of Work (PoW), Proof of Stake (PoS), Proof of Authority (PoA), Practical Byzantine Fault Tolerance (PBDT), Delegated Proof of Stake (DPoS), and many more [24]. Trust can then be established among parties who do not trust each other, and no external intermediary is needed to validate the data.

Blockchain can be categorized into permissioned or permissionless based on who can access the blockchain network. It can also be classified into public, private, and consortium blockchain based on how the permissions to write to the blockchain network are assigned [25]. There also exist hybrid ones with deferred and limited access to specific datasets for as long as the cryptographically selected methods are valid.

Blockchain can register, store and transfer any type of assets [3], including cryptocurrencies and any kind of contract and property. Blockchain can thus be used, for example, in proof of identity and ownership as well as protection of digital rights [5][16][26][27], although they work best with small data that can easily be serialized.

The fundamental blockchain technology exhibits a few key features that can bring significant benefits:

- Decentralization. It is a peer-to-peer distributed system that allows the participation of all parties and their access to data without the need of central authorities or intermediaries (no supervision), which provides robustness, resilience (no single point of failure), trustworthiness, and durability [28].

- Consensus mechanism. It provides self-organization and coordination mechanisms.

- Data integrity. The hash values in the blocks make it easy to identify data compromise.

- Privacy mechanisms. It provides pseudonymity for privacy preservation.

- Smart contract and autonomy. Smart contracts can execute predefined logic automatically when the terms on the contract are fulfilled. Blockchain smart contracts can be executed without a trusted third party. It has advantages like "transparency, accuracy, speed, security, efficiency, and trust" [29].

- Data transparency, accountability, and traceability support. The stored data cannot be altered. It provides a complete history of transactions, allowing data to be shared/exchanged securely and trustworthy in a lowtrust environment without a third party's supervision or intermediation.

- Cryptocurrency and social currency. It provides incentive mechanisms and financial innovations.

More technical details on blockchain technology are out of the scope of this paper, but interested readers can refer to literature like [30][31][32].

\section{METHODOLOGY}

We followed the tertiary review guidelines described in [18] for our study. We have searched in Scopus and Web of Science databases using the search terms "blockchain" AND "sustainability OR sustainable". We included only journal papers and (systematic) reviews. After the abstract screening of the 55 identified papers from keyword search, 30 papers were included for full-text assessment. 24 out of the 30 papers were found to be relevant to our research questions. Four more papers were identified using backward 
snowballing from the 24 papers. Finally, 28 papers were included in the qualitative synthesis. We followed the thematic analysis methodology [19] and used a qualitative analysis tool "Dedoose" ${ }^{1}$ to code the papers. The codes were analyzed and synthesized in an iterative process, and three authors were involved. Each selected paper was reviewed by one of the authors and coded with regard to the RQs. At least one other author validated the result of each paper. Consensus meetings were carried out when discrepancies arose.

To answer RQ1, i.e., for the mapping of blockchain impacts on sustainability to SDGs, we conducted a consensus-based expert elicitation process, as documented by previous studies on SDGs [33][34][35]. Three authors with different backgrounds and expertise from software engineering, sociology, and engineering performed the SDG mapping analysis. As the selected papers often do not directly connect blockchain and SDGs, we extracted documented blockchain impacts on sustainability (as codes in Dedoose) and mapped these impacts to concrete SDGs at the target level. We considered it acceptable evidence when there is a documented use case, implementation, or proposal on potential impacts on sustainability from the surveyed papers.

Drivers and barriers are factors that motivate or hinder the adoption of blockchain for sustainable development. They are often the two sides of the same coin. Papers often mentioned the barriers or challenges explicitly, but very few papers did mention drivers. To answer RQ2, we identified and extracted drivers from the descriptions in the papers. For example, when blockchain is used to solve specific domain challenges or needs. Blockchain key features are also considered as technical drivers. In some cases, we extracted barriers from the challenges, threats, and weaknesses listed in the paper, and extracted drivers from benefits, strengths, and opportunities in the Strengths, Weaknesses, Opportunities, and Threats (SWOT) analysis (e.g., [36]).

To answer RQ3, we used thematic analysis and summarized research gaps and challenges proposed in the surveyed papers.

\section{FINDINGS}

Some of our analyzed papers focused on summarizing blockchain and sustainability in different application domains. The main application domains the papers focused on are shown in Table 1 indicating that 11 out of the 28 papers focus on supply chain and logistics. Four papers are about manufacturing and industry 4.0. Three papers are on smart cities, covering several domains, such as energy, transport, health, and waste management. In addition, energy, transportation and finance (including Bitcoin) domains each has two papers. A few of our analyzed papers performed the survey by focusing on a particular theme. Two papers focused on studying the traceability aspect of blockchain. The other themes studied by one paper each include standards, law and policy, and research topics.

Our survey was conducted in the early part of 2021. Thus, we included only one article in 2021 in our study. Eleven of our studied papers were published in 2020, 10 were published in 2019, and four and two were published in 2018 and 2017, respectively. The rapid increase in the number of surveys shows a growing interest in blockchain and sustainability.

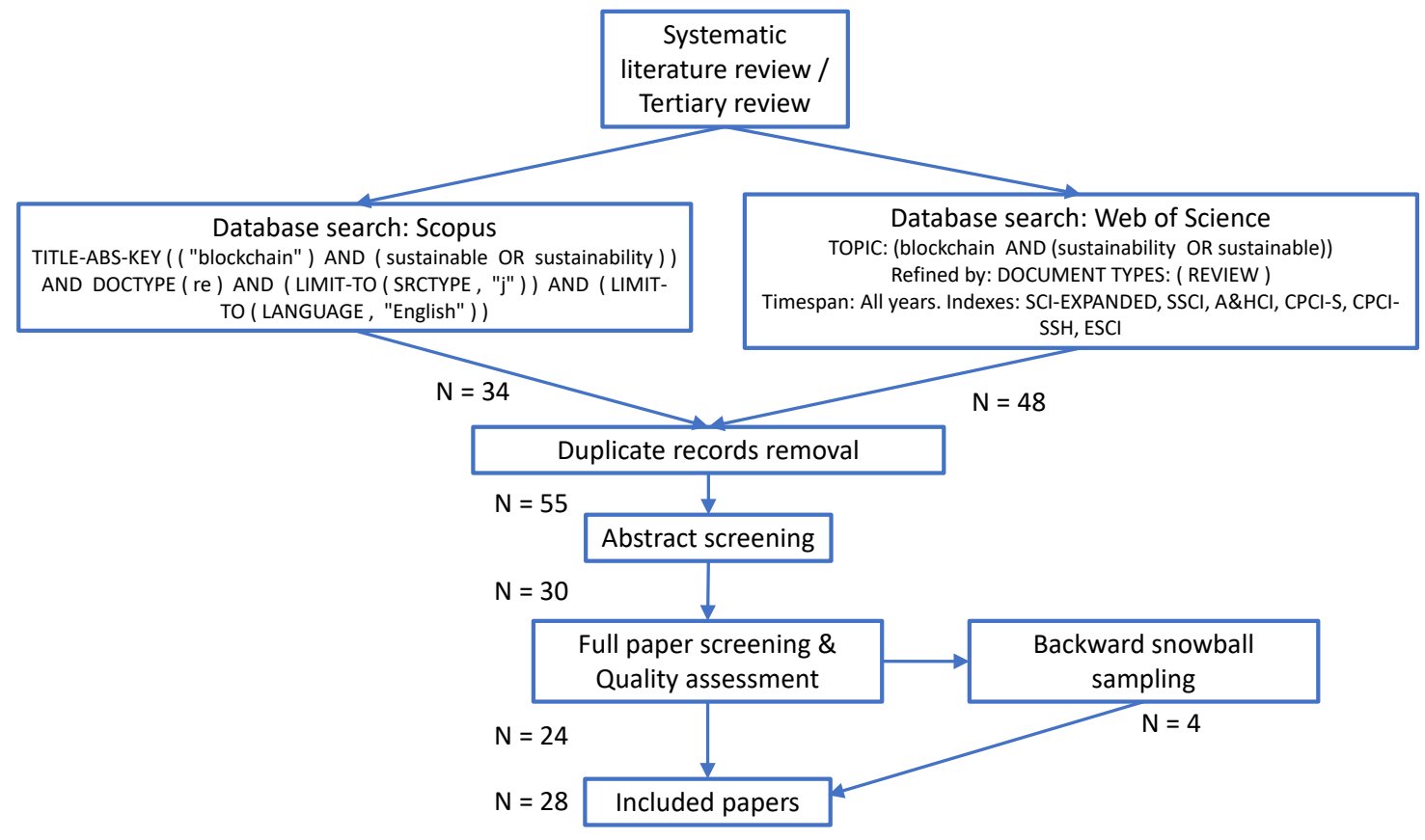

Figure 1 Flowchart of the tertiary review

\footnotetext{
${ }^{1}$ The Dedoose tool, see: https://www.dedoose.com/
} 

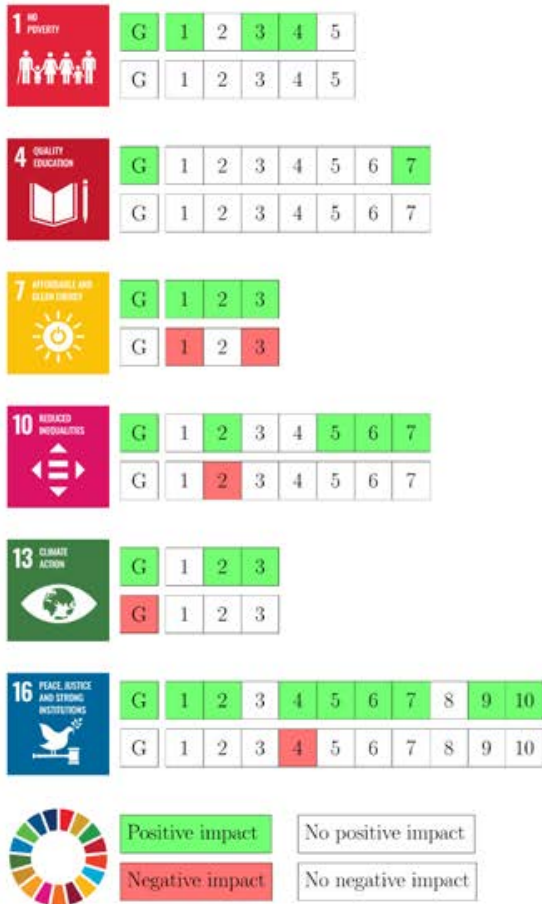

Ponitive inst
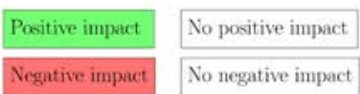
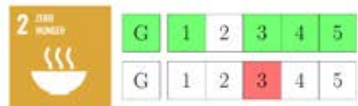

$3=1$

$-46$
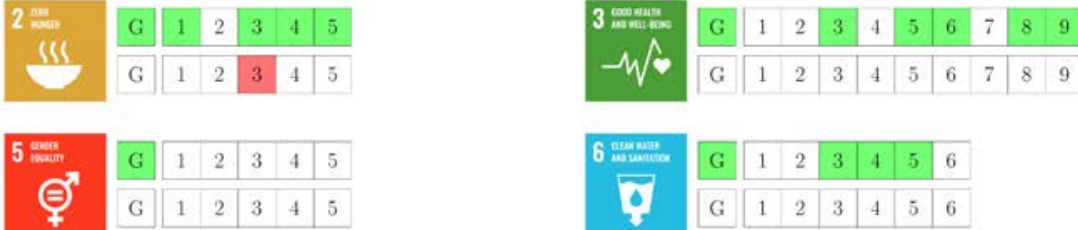

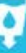

\begin{tabular}{l|l|l|l|l|l|l|}
\hline G & 1 & 2 & 3 & 4 & 5 & 6 \\
\hline
\end{tabular}
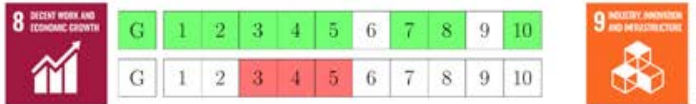

\begin{tabular}{l|l|l|l|l|l|}
\hline G & 1 & 2 & 3 & 4 & 5 \\
\hline
\end{tabular}

48

\begin{tabular}{l|l|l|l|l|l|} 
G & 1 & 2 & 3 & 4 & 5 \\
\hline
\end{tabular}
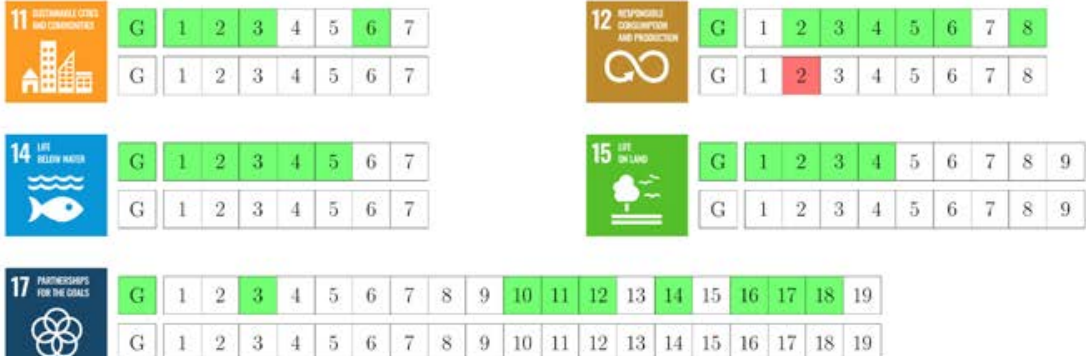

\begin{tabular}{|l|l|l|l|l|l|l|l|l|l|l|l|l|l|l|l|l|l|l|l|}
\hline $\mathrm{G}$ & 1 & 2 & 3 & 4 & 5 & 6 & 7 & 8 & 9 & 10 & 11 & 12 & 13 & 14 & 15 & 16 & 17 & 18 & 19 \\
\hline
\end{tabular}

Figure 2 Overview of blockchain's potential impacts on SDGs based on the reviewed papers. The numbers in the boxes represent the targets of the SDG. "G" in the box represents the SDG in general. The green box indicates a positive impact on a specific target of the SDG or the SDG in general, while the red box indicates a negative impact. A white box indicates that no impact (either positive or negative) has been identified from the reviewed papers.

TABLE 1 OVERVIEW OF THE 28 REVIEWED PAPERS AND THEIR TOPICS

\begin{tabular}{|c|c|c|}
\hline Topics & Paper & $\begin{array}{c}\text { Number of } \\
\text { papers }\end{array}$ \\
\hline \multicolumn{3}{|l|}{ Application domain } \\
\hline $\begin{array}{l}\text { Supply chain and } \\
\text { logistics }\end{array}$ & $\begin{array}{l}{[5][9][11]^{2}[13][23][29]} \\
{[37][38][39][40][41]}\end{array}$ & 11 \\
\hline Energy & [6] [36] & 2 \\
\hline Smart cities & {$[4][16][26]$} & 3 \\
\hline $\begin{array}{l}\text { Manufacturing and } \\
\text { industry } 4.0\end{array}$ & {$[7][14][15][42]$} & 4 \\
\hline Transportation & {$[8][28]$} & 2 \\
\hline Finance /bitcoin & [3] [43] & 2 \\
\hline \multicolumn{3}{|c|}{ Cross-domain themes } \\
\hline Traceability & {$[11][12]$} & 2 \\
\hline Standards & [44] & 1 \\
\hline Law and policy & [45] & 1 \\
\hline Research topics & [2] & 1 \\
\hline
\end{tabular}

\section{A. THE RESULTS OF RQ1}

The results of RQ1 are summarized in Figure 2 and show that blockchain has positive impacts on all 17 SDGs with direct impacts on 73 SDG targets, while negative impacts are experienced in 10 targets of $8 \mathrm{SDGs}^{3}$. Examples of blockchain's impact on SDGs are given in this Section. A complete list of papers including blockchain's impact on SDGs is given in Tables A-1 and A-2 in the Appendix.

\footnotetext{
${ }^{2}$ This paper addressed agri-food traceability and we placed them both under "supply chain and logistics" and "traceability". Other papers are placed under only one category.
}

\section{1) POSITIVE IMPACTS ON SDGS}

1.1) SDG 1 - No poverty

This SDG "calls for an end to poverty in all its manifestations by 2030" [68]. To explain SDGs and put the discussion in context, similar to this SDG, each subsection later starts with an introductory paragraph on the specific SDG based on the definitions from the online SDG explorer [68].

Blockchain contributes to SDG 1 through indirect impacts, such as preventing fraud and corruption in distributing food. Blockchain technology holds potential for mitigating corruption and can "break down the barriers that have impeded previous attempts to end poverty" [44]. For example, the United Nations (UN) humanitarian aid project distributed food in rural areas of Pakistan, utilizing blockchain to register funds and all types of transactions to assure transparency and security in the process [6]. Another example is the application of blockchain in the delivery of food vouchers to Syrian refugees [9][46].

Cryptocurrency and blockchain's decentralization feature fights against poverty. [46] claims that blockchainbased social currency may contribute to SDG 1 . An example from Cyprus, where people began converting money in their bank accounts to Bitcoin when the government planned to

\footnotetext{
${ }^{3}$ We counted only the specific targets with direct impacts. If blockchain only impacts an SDG in general (i.e., "G"-boxes in Figure 2), it is not included in the counting.
} 
seize cash in the country's bank accounts, has been proclaimed to showcase the potential of cryptocurrencies as a potential tool to fight poverty [43].

Blockchain can address power imbalance and allow a fairer value distribution of the supply chain. Bext360 coffee project deployed blockchain to address poverty and secure fairer and faster payment to smallholder farmers [9]. [36] lifts an example of favorable policy support compliant with the poverty alleviation strategy, which encourages the development of blockchain-based distributed Photovoltaic (PV) projects, allowing PV owners to sell energy through secure trading platforms and ensure a steady income.

\section{2) SDG 2 - Zero hunger}

The aim of this goal is "to end hunger and all forms of malnutrition by 2030", and further, to achieve "universal access to safe, nutritious and sufficient food throughout the year" [68].

Blockchain leads to reduced food waste. An untargeted food recall is the main cause of food wastes [37]. Blockchainbased traceability can improve recall efficiency and significantly reduce food waste and loss. It is an efficient tool to meet the consumers' concerns about the origin of their food and drinks and improve traceability and integrity in global food supply chains. Tracking food products can also fight against fraud and counterfeited products, ensure food quality, and reduce food recall and waste [11][12][37][39][41], which contributes to secure access to safe, nutritious and sufficient food (SDG target 2.1). Several use cases related to traceability for food supply chain have been analyzed in [41], for example, Alibaba ("Food trust framework" in global food supply chains), Walmart (tracking of Chinese pork and U.S. mango), Intel (seafood supply chain), and Bext360 (coffee supply chain).

Blockchain facilitates sustainable agriculture. Blockchain technology combined with IoT and big data analysis can improve crop or food production and encourage food producers to pursue sustainable practices in agriculture (SDG targets 2.3 and 2.4). [42] recommended applying blockchain and smart contracts in the plantation, harvesting, and milling process in the palm oil industry, such as using blockchain to enhance the product traceability across the supply chain and applying smart contracts to decide the premium price for products with good quality. Belagricola tracks grains and ensures their quality with the help of IoT and smart contracts, where warnings can be sent via a smart contract to prevent further damage when abnormal conditions are detected by IoT sensors [37]. [47] has analyzed blockchain's main applications in the agri-food value chain, i.e., traceability, manufacturing, information security, and sustainable water management (e.g., water trading for smart irrigation), and outlined blockchain's potential and implications for the performance improvements in the agrifood value chain, for example, regarding food safety, quality, and traceability.
1.3) SDG 3-Good health and well-being

This third SDG aims to "ensure health and well-being for all, at every stage of life" [68].

Blockchain supports secure and trustworthy infrastructure for healthcare applications. This impact is brought by blockchain's ability to ensure the transparency of medical data and improve trust in transactions in the medical value chain. A good number of applications, e.g., [4][16][28][41][46], in the healthcare domain (contribute to SDG target 3.8) are related to this. Blockchain can significantly reduce the development cost for new drugs and diagnostic tools due to improved transparency and trust [16]. Example use cases include medical data sharing among cloud service providers using blockchain-enhanced data security [43]; medical data access control associated with tracking sensitive data and enhanced security utilizing immutability and autonomy properties of blockchain; and improving clinical trials process with security mechanisms to avoid unauthorized manipulation [16].

Blockchain leads to automatic medical regulatory and standards compliance. IoT integrated blockchain traceability can monitor and track the conditions in the food and medical product supply chain (pollutions included), while smart contracts can automatically verify and enforce the compliance of the quality control and regulatory requirements. These contribute to several targets in SDG 3, including SDG targets 3.3, 3.5, and 3.9. Examples include the Chronicled, Modum, and Gemalto use cases illustrated in [41]. A blockchainenabled system focused on real-time tracking of cannabis plants from production to destination to impede illegal markets [16] is an example regarding SDG 3.5 (drug abuse).

Blockchain can create transparent, interoperable, and connective networks, which could make COVID-19 "a compelling case for the wider integration of blockchain", according to the World Economic Forum (WEF) [48]. For example, Spanish researchers piloted using a blockchain App to monitor the pandemic outbreak and support health officials with smarter decisions [4][49]. Blockchain also facilitates systems improving municipal health indexes, reducing garbage deposited in the municipal landfill, and potentially reduce diseases [46] (impacts on SDG targets 3.3 and 3.9). Furthermore, blockchain-empowered origin tracking and traceability in the food supply chain can ensure food safety and address the challenge of foodborne outbreaks for retailers [39].

1.4) SDG 4 - Quality education

This SDG aims to "ensure inclusive and equitable quality education and promote lifelong learning opportunities for all" [68].

Blockchain provides immutable and auditable certificates of learning achievements. Blockchain ensures secure and tamper-proof storage of educational data and documents and facilitates secure and privacy-preserving sharing and verification of learning achievements. Various applications of blockchain-based systems for education and learning have been proposed, e.g., [4][16], to keep an 
immutable and secure record of the educational process, including data sharing and storage, verification of student records, and accreditation. The purpose is to improve digital platforms for decentralized learning, in particular, related to the life-long volunteering in personal development (the socalled volunteer services [16]), protect copyrights and digital rights, maintain the trustworthiness of the educational certificates and the intellectual rights, and mitigate fraud and establish a scholarly reputation.

Blockchain improves awareness and transition to sustainable practices. Regarding SDG target 4.7 , an example is an application [46], which utilized blockchain to create awareness among young people and children about ecologically correct behavior and encourage recycling solid domestic wastes by motivating and training people.

\section{5) SDG 5 - Gender equality}

This fifth SDG aims to "achieve gender equality and empower all women and girls" [68].

Blockchain contributes to inclusion and equality. Our studied literature did not provide examples and use cases directly related to this SDG. However, the blockchain implementation could influence or catalyze democratization processes, promote transparency and accountability of and in institutions and amongst stakeholders. Blockchain can verify and authenticate human identity, provenance, and transactions and offer transparency and accountability, contributing to breaking down the barriers to reduce inequality [44], thus having potential positive impacts on gender equality.

\section{6) SDG 6 - Clean water and sanitation}

This SDG aims to "ensure the availability and sustainable management of water and sanitation for all" [68]. This domain is emphasized as at "the very core of sustainable development" because access to clean water is critical to the survival of people and the planet in general [68].

Blockchain improves access to affordable and reliable water resources. Combined with IoT, blockchain's ability to improve the monitoring and tracking of products and processes also applies to water quality and consumption. Regarding SDG targets 6.3, 6.4, and 6.5, blockchain can be used to monitor water quality and consumption, and regulate water usage for different areas, with benefits like enhanced security and transparency, reduced operational cost, and overall efficiency [26][50]. A blockchain-based gaming platform for water consumption efficiency was mentioned in [16], where blockchain mechanisms were utilized to engage users and ensure the correctness and privacy-preserving in water consumption reporting.

1.7) SDG 7 - Affordable and clean energy

This SDG aims to "ensure access to affordable, reliable, sustainable, and modern energy for all" [68].

Blockchain provides a secure and trustworthy infrastructure for energy systems. Energy is a domain where many blockchain-based use cases and systems have been proposed and implemented [4][6][16][26][28][36] [42][44]. Blockchain technology can overcome the obstacles that have hindered previous attempts to deliver sustainable energy. [6] proposed a blockchain applications framework in smart grid security and data protection with blockchain as a cyber layer, illustrated the blockchain-based microgrid automation, and analyzed blockchain's readiness in the smart grid. As real-life examples, the paper also listed corporations that take the role of retail energy intermediaries and exploit blockchain to become more affordable and competitive. Blockchain has been adopted as countermeasures to cyberphysical attacks, enhancing the power grid's security, privacy, and robustness [6]. Blockchain also guarantees smart meter readings' transparency and data security in Smart Energy Grids [16][26].

Blockchain improves access to affordable and reliable energy resources. Regarding SDG target 7.1 ("access to affordable, reliable, and modern energy services"), blockchain has been applied to facilitate and enhance energy services and new business models, such as peer-to-peer (P2P) energy trading, electric vehicle applications, grid security applications, microgrid operations, and control application [6]. The increasing installation of distributed energy systems (such as rooftop solar photovoltaic (PV) panels, micro-wind or hydro generation systems) leads to the increase of microgrids and the emergence of prosumers, who produce and consume electrical energy in a local area. Microgrids increase the utilization of local energy generation, as they can reduce energy loss and thus improve energy efficiency. Microgrids are considered more resilient than traditional centralized power plants and are also referred to as citizen's utilities due to the energy generation and distribution at the citizen level [6][43].

Blockchain enables new energy business models. Blockchain plays a significant role in energy trading, e.g., for prosumers, energy storage systems, and electric vehicles. It also supports new business models on P2P energy trading transactions [6][16][26]. Regarding SDG target 7.2 (increase the share of renewable energy), blockchain supports secure, reliable, and efficient energy trading of distributed renewable energy (e.g., PV, wind, hydro) based on P2P decentralized architecture, smart contract and automatic negotiation, verifiability, and traceability. Two papers have analyzed the role of blockchain in improving the competitiveness and sustainability of the distributed PV industry [36] and the palm oil industry [42]. Replacing fossil diesel with palm-derived biodiesel can effectively reduce $\mathrm{CO} 2$ emissions and alleviate fossil fuel dependency [42]. Blockchain can be applied across multiple stakeholders for the sustainable palm oil industry utilizing blockchain's features related to traceability, cybersecurity, and smart contracts for fair pricing. Regarding SDG 


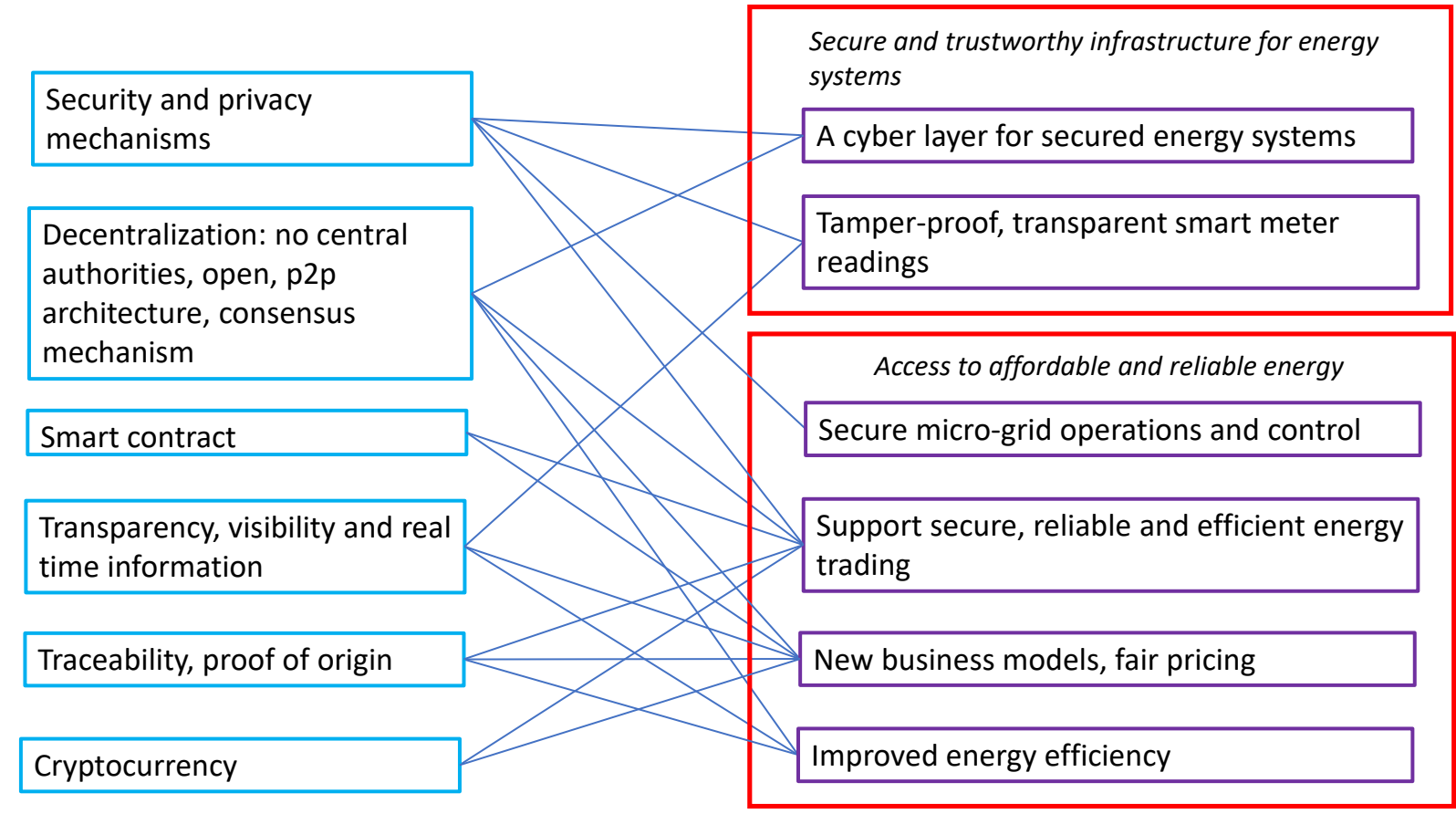

Figure 3 Blockchain's contribution to positive impacts on SDG 7

target 7.3 (improve energy efficiency), blockchain offers transparency and real-time information and improved traceability, enabling reliable real-time data analysis of energy transactions and strengthening energy resources planning and management [4][26].

A summary of the relationship between blockchain's features and their impacts on SDG 7 is shown in Figure 3 .

1.8) SDG 8 - Decent work and economic growth

This SDG aims to "promote sustained, inclusive and sustainable economic growth, full and productive employment and decent work for all' [68].

Blockchain improves efficiency and cost reduction. As shown in Figure 4, blockchain has been used to ensure security, privacy-preserving and transparency for real-time information sharing and reduce information asymmetry among stakeholders [8][13][15]. The transparency, visibility and real-time information can enable efficient resource allocation and improve decision making. The disintermediation and smart contracts can automate business processes and improve the process and operational efficiency. Together they contribute to cost reduction related to, for example, execution of payments, automatic change of goods ownership in the supply chain, execution of energy trading transactions, as well as processes in smart manufacturing related to "searching, negotiation, transaction, and tracing, and carrying out integration" [14]. Blockchain enables finer granular traceability, reducing recall costs significantly [23][28]. It can automate supply chain certification processes and reduce regulatory compliance costs [28][41]. The automation eliminates paper records, saving time and cost. Blockchain can enhance coordination and improve efficiency in supply chains. [8] has detailed the benefits from blockchain adoption, among others, enhanced job performance, reduced rework and recall, reduced transaction delay, increased efficiency in trade contracts and harmonization of conflicting objectives.

Blockchain enables inclusive financial services. Blockchain has created new jobs and business models, e.g., within supply chain finance domains [13] and extended revenue streams [14]. Blockchain has been exploited to enable new business models and new services, for example, peer-topeer ( $\mathrm{P} 2 \mathrm{P}$ ) models in $\mathrm{P} 2 \mathrm{P}$ lending, leasing and financing, $\mathrm{P} 2 \mathrm{P}$ energy trading, as well as connected vehicle services and other new types of business models for the automotive industry [15][16]. Furthermore, blockchain's inherent features promote a collaborative-based sharing economy and provide even value distribution [13]. For example, blockchain presents a secure and transparent infrastructure for a social production model where the created value and rewards are distributed fairly among the contributors through a cryptocurrency-based economy [16]. All the above contribute to industry competitiveness, economic productivity and growth, as well as resource efficiency, impacting SDG targets 8.1-8.4.

Blockchain's decentralization and cryptocurrency leads to financial inclusion. Blockchain allows for re-balancing of power and fairer value distribution, enabling innovations in financial services and contributing to financial inclusion. This has positive impacts on several SDG targets which address financial inclusion from various aspects: 1.4 (equal rights to 
economic resources and financial services), 2.3 (small-scale food producers' access to financial services), 8.3 (encourage SMEs' growth through access to financial services), 8.10 (inclusive access to banking, insurance and financial services), 9.3 (increase small-scale industrial enterprises' access to financial services), and 10.2 (economic inclusion of all). As the same examples and use cases can illustrate blockchain's impacts on these different targets, we present them together in the following paragraph to avoid repetition.

The original applications of blockchain and cryptocurrency were in the finance and banking sector. However, the applications have been extended to other sectors using blockchain as e-commerce platforms and ownership management systems [16]. Blockchain (cryptocurrency) is an important instrument to facilitate the adoption of microfinance or remittances for rural smallholder farmers and their families as the transaction costs can be reduced by eliminating intermediaries [43]. Notably, blockchain-based financial services platforms are beneficial to SMEs, which generally have difficulty raising funds. Examples of such platforms include Chained Finance and IBM's financial services platform for supply chains [9]. [46] described an example blockchain-enabled system that offered additional earnings to low-income families and boosted the local economy via green money circulation. Blockchain's decentralized network, consensus mechanism, and data integrity allow everyone to generate content, participate in the entire product lifecycle and collaborate efficiently, promoting the inclusion of SMEs and consumers in, e.g., collaborative product design, open and social manufacturing [14]. Smart contracts have been piloted within financial transactions and settlements, such as the digital wallet blockchain initiative for automated payment in electric vehicle charging and the automatic payment for the transfer of cargo ownership in supply chain management [9]. Smart contracts have been applied to financial loan management to process loans or subsidies among SMEs, e.g., lower interest rates are given to companies committed to fulfilling the CSPO standard based on the CSPO certification status [42].

Blockchain ensures human rights and fair working conditions and reduces unethical and illegal practices. This impacts SDG targets 8.5, 8.7 and 8.8, for example, through monitoring and tracking sustainable conditions and implementing or managing suitable corrective activities [8][29][41][44]. Blockchain is a tool for verifying sustainability with meaningful and quantifiable indicators [13]. Blockchain-empowered traceability can monitor and verify working conditions and practices, such as child labor, modern slavery in the industry, and other discrimination or inequality related conditions. Therefore, blockchain can secure human rights, fair working practices and fair trade and potentially stop unethical and illegal practices. This also contributes to reducing inequality and eliminating discrimination.
Blockchain features

\begin{tabular}{|c|c|}
\hline (Combined with loT, Al) & Cost reduction and improved efficiency \\
\hline & $\begin{array}{l}\text { Reduced governance cost due to automated } \\
\text { certification process and compliance }\end{array}$ \\
\hline $\begin{array}{l}\text { Security and privacy } \\
\text { mechanisms }\end{array}$ & $\begin{array}{l}\text { Improved process efficiency and resource } \\
\text { efficiency }\end{array}$ \\
\hline $\begin{array}{l}\text { Transparency, visibility and real } \\
\text { time information }\end{array}$ & Improved recall efficiency, reduced recall cost \\
\hline Smart contract & $\begin{array}{l}\text { Lower cost and improved efficiency due to } \\
\text { elimination of intermediaries }\end{array}$ \\
\hline $\begin{array}{l}\text { Decentralization: no central } \\
\text { authorities, p2p architecture, } \\
\text { consensus mechanism }\end{array}$ & $\begin{array}{l}\text { Ensure human rights and fair working conditions, } \\
\text { social inclusion }\end{array}$ \\
\hline Cryptocurrency & $\begin{array}{l}\text { New business models, new and inclusive financial } \\
\text { services }\end{array}$ \\
\hline
\end{tabular}


1.9) SDG 9 - Industry, innovation and infrastructure

This SDG aims to "build resilient infrastructure, promote inclusive and sustainable industrialization and foster innovation" [68].

Blockchain leads to industrial sustainability. Blockchain's impact on SDG target 9.2 (inclusive and sustainable industrialization) is through enabling secure and reliable manufacturing systems with automated workflows and efficient operations [4]. Smart and sustainable manufacturing is based on the industrial IoT that utilizes ad-hoc connections of numerous sensors and connected devices to monitor and track product life cycle and automate workflows. Blockchain provides a resilient and sustainable ICT infrastructure for smart manufacturing and industry $4.0[4][7][14][41]$ and helps address challenges in sustainable manufacturing and product life cycle management [14]. [14] presents various models of blockchain-empowered manufacturing paradigms and architectures and explains why and how blockchain and smart contracts can be integrated into key enabling technologies for manufacturing systems, including Industrial IoT, equipment management, digital twin, enterprise resource sharing and planning, as well as execution and operation scheduling.

The application of blockchain in software-based manufacturing can increase productivity and quality control, reducing the costs, such as tracking in inspections, inventory management, maintenance or recycling tasks and ownership issues. The Renault use case [15] is an example implementation that connects each car maintenance book to the vehicle's blockchain-enhanced digital twin, where blockchain brings benefits like tamper-proof data, traceability and visibility.

Blockchain helps verification of intellectual properties and digital rights. Regarding SDG target 9.5 (scientific research and innovation), blockchain can encourage, support, and enhance open innovation and open science concerning access to the scientific results and the scientific process. For example, blockchain is used to credit researchers for their respective scientific work and protect authors and software owners' intellectual properties and digital rights, ensuring the sustainability of scientific research and innovation [16].

\subsection{0) SDG 10 - Reduced inequalities}

The aim of SDG 10 is to "reduce inequality within and among countries" [68]. This SDG emphasizes inequalities in income and those based on age, sex, disability, race, ethnicity, origin, religion, or economic or other status regarding inequalities within countries. Regarding inequalities among countries, this goal addresses "those related to representation, migration and development assistance" [68].

Blockchain promotes social equality and inclusion. A blockchain network has inherent equality and inclusion. All participants have the same power. There is no central authority. Everyone has access to an identical copy of data (transparency and information symmetry), everyone can participate in the decentralized decision based on consensus mechanisms. This allows for re-balancing power and fairer value distribution, offering opportunities, e.g., for small businesses [9].

Corruption and manipulation of reputation data or ratings in centralized services, including banks and governments, impedes the trust needed to ensure the equal and fair distribution of power and wealth in any society or economy. Blockchain creates trust between users and content and facilitates fair trade by coordinating conflicting interests towards common goals [44]. It can secure and establish good trust among involved parties in the value chain based on decentralization, accountability and transparency, trust and risk reduction. Decentralization and transparency supported by blockchain can benefit less powerful parties in the supply chain [9][51]. This has the potential to socially integrate low-income, marginalized or market-restricted groups into the formal market [46].

Regarding political inclusion and decision making, blockchain allows for collaborative and decentralized decision making, e.g., e-voting [26], and collaborative product design and crowdsourcing in manufacturing [14], collaborative urban decision making [16]. Blockchain's applications in banking and financing systems based on cryptocurrencies have social implications for changing organizations concerning SDG targets 10.5 and 10.6 .

\subsection{1) SDG 11 - Sustainable cities and communities}

This goal aims to "make cities and human settlements inclusive, safe, resilient and sustainable" [68]. It is specifically targeted at urban areas, based on a rationale that cities and human settlements can function as incubators for innovation and ingenuity, driving sustainable development.

Smart contracts avoid fraud and double registration of properties. Regarding SDG target 11.1 (access to adequate, safe, and affordable housing), [26] discussed how smart contracts could facilitate property-, land-, and housing registration and, in general, support property development processes, particularly to avoid issues related to fraud and double registration.

Blockchain improves road traffic safety and sustainability. Blockchain provides privacy protection, secure and privacypreserve data exchange and communication. It can solve trust challenges for vehicle networks and Intelligent Traffic Systems (ITS), providing the basis for a large number of sustainable and safe transport services, systems and business models through innovations based on "electric", "connected" and "autonomous" vehicles [15][16][26][28]. Compared to the mainstream centralized ITS system, blockchain is expected to enable a decentralized, secured, and trusted autonomous ITS ecosystem and facilitate digital and physical assets [16]. Blockchain smart contract enables automatic negotiation for electric vehicle (EV) charging services, stimulate EV market growth and reduce greenhouse gas (GHG) emission [6][15][16][28]. Blockchain's transparency and security mechanisms facilitate fraud reduction of vehicle information management and remote vehicle software version update [16]. Blockchain's features for secure data storage and verification of digital identity can address problems by the rise of sharing economy and collaborative consumption, such as trust issues and stranger sharing. For example, in ride-sharing services, blockchain can securely verify the digital identities of the drivers or customers and grant them access to the data of shared vehicles through the verified digital identities [26]. Cryptocurrency can be used as a financial incentive for urban transportation sustainability, e.g., motivating urban cycling [16].

Blockchain promotes environmentally friendly practices. Regarding SDG target 11.6 (environmental impact of cities, focusing on air quality and waste management), blockchain's traceability and transparency are used for fraud protection and waste reduction and management [14][16][26][46]. Blockchain's visibility and transparency, and cryptocurrency can motivate the 
transition to sustainable practices, such as recycling and efficient waste management (solid waste and e-waste), and sustainable behavior among motorists and other road-users [16][28].

In combination with IoT, blockchain technology can be used for transparent and secure monitoring and tracking the level of pollutants, increasing the awareness of environmental impacts, e.g., regarding air quality and pollutants, thus contributing to $\mathrm{CO} 2$ emission reduction [16][26].

\subsection{2) SDG 12 - Responsible consumption and production} This SDG calls for ensuring "sustainable consumption and production patterns". Here, it is emphasized that "economic growth and development require the production of goods and services that improve the quality of life", and that "sustainable growth and development require minimizing the natural resources and toxic materials used, and the waste and pollutants generated", throughout the production as well as consumption [68].

Blockchain encourages responsible consumption and production. Blockchain applications can improve decision making based on real-time data collection and analysis and facilitate efficient use of natural resources (SDG target 12.2) [7][8][13][14][16][41]. Regarding SDG target 12.5, blockchain's data transparency and traceability can enable a circular economy and reduce waste through better decision-making and planning based on product life cycle data. For example, using an IoTintegrated blockchain system, accurate and tamper-proof data on product life cycle can be provided as reliable information for effective circular economy planning regarding product recycling and remanufacturing [14]. In addition, waste reduction and management as described for SDG 11.6 (see Section IV.A.1.11), in particular, the application of solid waste management and the e-waste handling system using blockchain, are examples of blockchain's potential impacts on SDG targets 12.4 and 12.5.

Blockchain enhances the reputation of companies following sustainable practices. This impacts SDG target 12.6 (encourage companies to adopt sustainable practices and to incorporate sustainability information in the reporting cycle) and 12.8 ("ensure relevant information and awareness for sustainable development and lifestyles in harmony with nature"). Blockchain has the potential to enable sustainability verification through more quantifiable and meaningful indicators [41].

Blockchain's transparency and traceability enhance the visibility of information related to sustainability, such as the carbon footprints in the supply chain, and can thus improve the awareness of the environmental impacts. Examples include emission trading based on carbon footprints in fashion apparel manufacturing [14] and using cryptocurrency as a reward mechanism to motivate the recycling of solid domestic waste and enable efficient waste management [16][46].

The awareness-raising can encourage people and organizations to adopt sustainable behavior (SDG target 12.8). Traceability as a strategic tool to monitor environmental impacts and regulatory compliance can encourage companies to be more sustainable (SDG target 12.6). As an example, blockchain traceability provides tamper-proof data for carbon tax calculation, which will encourage companies to restructure their supply chains for lower carbon footprints [26]. In addition, companies in global supply chains face more pressure for traceability as they need to adapt to different policies in different areas. "By applying blockchain, globalized standardization can be adaptable for all countries and regions, and they can save companies from duplicative works" [37]. Furthermore, blockchain traceability is an affordable mechanism to differentiate sustainable products and practices from nonsustainable ones [42] and facilitate the verification of ecolabelling and certifications [38]. Thus, it adds value and enhances the reputation of companies that adopt sustainable practices. Further examples include using blockchain and smart devices to advance carbon emission compliance and trading, e.g., in the fashion apparel manufacturing industry [11][14][16], and a reputation-based mechanism using blockchain to encourage the adoption of a long-term solution for reducing emissions [16]. By enabling users to precisely monitor their energy use and the corresponding energy mix composition, e.g., through trading certificates, blockchain can help avoid energy waste, promote the use of green energy and decrease the use of fossil fuels [4].

\subsection{3) SDG 13 - Climate action}

This SDG call for "urgent action to combat climate change and its impacts". Climate change is stressed as "the single greatest threat to development", and its impacts "disproportionately burden the poorest and most vulnerable". Thus, combating climate change, minimizing its disruptions is considered integral to successful SDG implementation [68].

Blockchain contributes to pollution reduction and environmental degradation. Blockchain boosts organizations' capability for combating climate changes (SDG target 13.1). For example, in blockchain-enabled sustainable supply chain and logistics [8][13][37], efficient resource allocation and improved decision making based on visibility and transparency of data lead to a reduction of fuel and energy consumption, lowering GHG emissions, alleviating pollution and environmental degradation [8]. In the energy domain, blockchain supports low-carbon energy systems integrated with renewable energy and high energy efficiency, such as the adoption of renewable energy (see description of SDG 7 in Section IV.A.1.7) and the substitution of conventional diesel with palm-derived bio-diesel case [42]. For low carbon mobility, smart contracts enhance EV charging services and stimulate EV market, and blockchain-empowered new ITS and services reduce road traffic congestion, improve safety, and reduce energy consumption and pollution [28]. Other examples include improved carbon emission compliance and trading [8][16], constructive involvement of citizens in environment quality monitoring to boost awareness on city health [16], and waste reduction and management [16][28][46].

Regarding SDG target 13.2 from a policy aspect, blockchain transparency improves visibility, which can bring attention to the need for regulations within and between countries and catalyze the development of policies and regulations for sustainable development [37].

Concerning SDG target 13.3 (awareness-raising and early warning), building on blockchain features of information sharing, transparency and decentralization, blockchain applications are used in monitoring and tracking the level of pollutants, improving air quality and pollutant awareness, contributing to $\mathrm{CO} 2$ emission reduction [16][26]. Blockchain's traceability also makes eco-labelling and certifications related to sustainability verifiable and trustworthy [38]. 
1.14) SDG 14 - Life below water

This SDG calls for conservation and sustainable utilization of "oceans, seas and marine resources for sustainable development". Apart from playing a significant role for the 37 $\%$ of the global population living in coastal communities, "coastal and maritime resources contribute an estimated USD 28 trillion to the global economy each year". Further, oceans also "help regulate the global ecosystem by absorbing heat and carbon dioxide from the atmosphere and protecting coastal areas from flooding and erosion" [68].

Blockchain improves the monitoring and protection of sustainable use of the oceanic ecosystem. A pilot project on blockchain-based traceability in the Indonesian fishing industry is described in [41]. Traditional seafood source tracking system is based on paperwork, and full quality control of seafood trades from hundreds of boats is challenging. It lacks supervision and is plagued by corruption, questionable practices, and problems such as fraud, overfishing, and illegal, unreported, and unregulated (IUU) fishing. Blockchain helps mitigate IUU fishing and stop illegal practices, including slavery, through traceability, transparency, and stakeholder engagement [13][41][52], thus contributing to fulfilling targets 14.1 to 14.5 [13][52].

\subsection{5) SDG 15 - Life on land}

This SDG aims to preserve diverse forms of life on land, calling for efforts to "protect, restore and promote sustainable use of terrestrial ecosystems, sustainably manage forests, combat desertification, and halt and reverse land degradation and halt biodiversity loss" [68].

Blockchain facilitates monitoring and sustainable use of the terrestrial ecosystem. For example, a blockchain-based approach was used to monitor the sand resources supply chain from mining to trading to prevent illegal sand mining, contributing to combating desertification (SDG target 15.3) [16]. The sustainable palm oil industry example mentioned in Section IV.A.1.7 can also contribute to holding deforestation (SDG target 15.2) [42]. Blockchain is also used for the traceability of wood products along the supply chain [13][23], affecting targets 15.1-15.4.

\subsection{6) SDG 16 - Peace, justice and strong institutions}

The goal of SDG 16 is to "promote peaceful and inclusive societies for sustainable development, provide access to justice for all and build effective, accountable and inclusive institutions at all levels". It rests on the rationale that "peace, justice, and effective, accountable and inclusive institutions are at the core of sustainable development" [68].

Blockchain prevents unethical and illegal practices and promotes peace. This has impacts on SDG targets 16.1-16.5, e.g., reducing all forms of violence, combating crimes, reducing corruption and bribery, and uncovering and ending unethical and illegal practices (fraudulency, unethical use of natural resources, child labor, etc.) [26][41]. As an example, Everledger's diamond certificate system uses the blockchain traceability of diamonds' provenance as a measure to eliminate the flow of diamonds mined inside conflict zones for financing wars [41].

Blockchain leads to more accountable institutions at all levels. This impacts SDG targets 16.6 and 16.8. Blockchain guarantees accountability with timestamped, immutable and auditable data and ensures transparency in value chains and amongst stakeholders [15][16][29][39]. Blockchain thus has a noticeable impact on society, law, and governance at various institutional levels. For example, blockchain allows the creation of Decentralized Autonomous Organizations (DAO), which has a potential impact on organizational design [13]. The previous sections on SDG 8 and 9 have described blockchain's positive impacts on various companies and organizations (manufacturers, supply chain partners, energy providers, farmers, etc.) regarding their effectiveness (improved efficiency), accountability and inclusiveness, which are also good examples illustrating blockchain's impacts on SDG target 16.6.

Blockchain facilitates smart and collaboration administration and governance. Blockchain's transparency and accountability impact smart governance and administrations [16][26]. It includes, for example, improved efficiency (lowering administrative cost, etc.) in public administration regarding service delivery and operation, accountable and transparent document sharing, and corruption and fraud prevention based on enhanced transparency.

An example of SDG target 16.4 (combat organized crime) is Estonia's e-residency and government-banked cryptocurrency (Estcoin) against counterfeiting and illegal use [43]. Another example is blockchain empowered digital identity and proof of ownership and digital rights [16].

Regarding SDG target 16.5 (reduce corruption and bribery), governments can reinforce transparency and avoid corruption [26][41] by utilizing blockchain to store and interconnect government records (incomes, expenses, contracts, etc.), as well as to secure online transactions [13]. For example, blockchain was applied in decentralized e-voting systems [4][26] to eliminate voter fraud. Blockchain ensures the anonymity, privacy, transparency and traceability of the voting process, contributing to SDG targets $16.5,16.6$ and 16.7. Blockchainbased applications for taxation can prevent tax revenue losses and prevent duplicated tax refunds [5].

Regarding SDG targets 16.7 (inclusive and participatory decision-making), blockchain's decentralization eliminates the central authority and control. It allows everyone to access the same data and participate in a consensus-based decentralized decision. At the same time, blockchain's transparency and immutability ensure the transparency and integrity of government information. This increases citizens' trust and encourages stronger inclusion and participation in democratic decision making and collaborative urban policy-making [4]. For example, in a disease spread scenario, blockchain helps manage individual health data more transparently and ethically, facilitating evidence-based collaborative decision making [16].

Regarding SDG target 16.9 (legal identity for all), digital identity is one key application of blockchain and also the basis for many other applications, for example, using blockchain to securely store, share and authorize information on digital identity and other information related to citizens, such as national identity, passports, birth and death registration, health and employment records [26].

Regarding SDG target 16.10 (ensure public access to information and fundamental freedom), various blockchainbased systems have been proposed to ensure that government documents can be shared with the public more securely and reliably [16], e.g., Dubai's e-Democracy [26]. 
1.17) SDG 17 - Partnerships for the goals

This final SDG builds on the rationale that, to achieve the SDGs, revitalization and enhancement of global partnerships, bringing together Governments, civil societies, the private sector, the UN system and other actors, is required. This SDG aims to "strengthen the means of implementation and revitalize these global partnerships for sustainable development" [68].

Blockchain facilitates the building of multi-stakeholder partnerships. Blockchain provides computational trust, reduces cyber-risks, assures information transparency and symmetry for all participants, facilitating transparency and accountability of the value chains and reducing risks. Thus it can build trust and enhance collaboration and cooperation across multiple stakeholders [7][9][13][14][16][23] [29][38][40][41][44][53]. Using smart contracts can improve trust and greatly speed up the transactions, substituting the letter of credit and securing the partnerships [37]. In particular, blockchain facilitates the establishment of trust in a low or no trust environment and facilitates greater collaboration, for example, among potential partners that never met earlier or may be far away from each other in complex global supply chains [28]. This has positive impacts on targets related to cooperation and collaboration and facilitates the building of multi-stakeholder partnerships in pursuing sustainable development globally; for example, SDG targets 17.16 and 17.17. Examples of applications of this advantage include securing and establishing good trust among involved parties in the value chain, reducing custody risk and securing ownership registration and cross-border asset transfers, transaction verification, theft prevention, tracking disruptions roots and propagation, addressing the holistic sources of risk, reducing inefficiencies in capacity reservations and backup sources [7][8][14][28][37][41].

Blockchain catalyzes the development of policies and regulations. This has positive impacts on SDG targets 17.13 and 17.14. Blockchain offers instruments for mapping norms, frameworks and policy-making [44]. For example, the improved visibility facilitates the determination and shaping of rules and governance norms at various levels such as transport, logistics, and supply chains, allowing for effective government supervision and enhancing policy coherence for sustainable development of the transport and logistics industry [8]. Blockchain can also help achieve global alignment in traceability and conservation of natural resources, supporting global standardization adapted to all countries [37].

Blockchain improves fair trade. Blockchain can potentially solve the challenges related to fake customers, and personal reputation records falsification through transparency and verifiability, facilitating e-commerce [23][39]. Blockchain can also simplify international trade finance through global interoperability [44]. Benefits brought by blockchain's application in the supply chain and its role in enabling trade, as estimated by WEF, "could increase worldwide GDP by almost $5 \%$ and total trade volume by $15 \%$ " [39]. These indicate positive impacts on SDG targets 17.10, 17.11, and 17.12.

\section{2) NEGATIVE IMPACTS ON SDGS}

Compared to blockchain's positive impacts on SDGs, we found very few discussions on negative impacts related to sustainability, and none of the papers explicitly mentioned negative impacts on SDGs. Below is a summary of the main negative impacts of SDGs from the surveyed papers.

Some blockchain technologies' energy intensiveness leads to wasted resources and high carbon footprints and GHG emissions. Proof of Work algorithms like Bitcoin is considered environmentally costly due to their energy intensiveness and wasted resources related to mining, validation of transactions and maintaining of the consensus [3][8][15][28][43][45]. Thus, it has potential negative impacts on SDG 7 (targets 7.1 and 7.3) regarding energy consumption and energy efficiency, SDG 8 (targets 8.4) and SDG 12 (target 12.2) regarding resource use and efficiency as well as SDG 13 regarding carbon footprints and GHG emission.

Costs and infrastructure, and training investment lead to inequality. Blockchain requires a high degree of computation, which affects its availability and scalability. The adoption of blockchain technology requires server infrastructure investment (including Internet connectivity) and additional implementation costs. Hardware and software upgrading is needed, implying increased costs associated with devices, operation, maintenance, and training. In addition, lack of expertise and skilled personal is another barrier for adoption. These may hinder blockchain as an affordable technology for all, in particular, for developing or underdeveloped countries, SMEs and small farmers with poor infrastructure and constraints in finance and skill [9][41][43]. It would then be difficult to realize the full potential of blockchain in the global supply chain, which depends on the participation of partners in the whole supply chain. Such economic and knowledge barriers have a potential negative impact on SDG 2 (target 2.3) regarding the accessibility of smallholder farmers, SDG 8 (target 8.3) and SDG 10 (target 10.2) regarding economic inclusion, and SDG 9 (target 9.2) regarding affordability and inclusiveness as well as increased consumption.

Anonymization and cryptocurrency may potentially be used for illegal activities. Blockchain's permissionless public systems might be used for illegal activities due to its anonymization. For example, cryptocurrencies have been linked to drug and weapon trading, money laundering, and financing of terrorism [3][9][43]. This indicates potential negative impacts on SDGs; for instance, SDG targets 16.4.

Blockchain can lead to job losses and job reskilling. Blockchain is based on disintermediation and distributed consensus. Blockchain adoption may result in job losses for current intermediaries in the short term, and job reskilling as new intermediaries offering new blockchain-based services may emerge [9], impacting SDG 8 (target 8.5).

\section{3) SUMMARY OF THE IMPACTS}

We have summarized the above identified blockchain's positive and negative impacts on SDGs through thematic analyses. The positive impacts are summarized in Table 2 . The blockchain's positive impact on sustainability can be classified into many codes, 24 categories, and five high-level themes: economic, environmental, social, governmental, and legal and regulatory. 
TABLE 2 THEMATIC OVERVIEW OF BLOCKCHAIN'S POSITIVE IMPACTS ON SUSTAINABILITY ${ }^{4}$

Categories and codes of the positive impacts on sustainability

\section{Economic impact:}

Cost reduction for companies and institutions [8][13]: elimination of paper records [8]; automated supply chain certification processes [41]; reduced regulatory compliance and verification costs [41]; cost reduction and improved efficiency due to removal of intermediaries from the market [8].

Increased dependability of systems and processes, and reputation enhancement [5]: enforcement of SLA (Service Level Agreement) satisfaction between participant [7]; integrity and traceability ensured product quality [7]; fraud prevention in trade [41]; improved food safety [37]; higher resilience [14]; cyber resiliency[15]; proof of sustainable practices [41]; provenance of products and ingredients/components [41]; transparency and visibility of data provenance [5].

Improved efficiency [37]: traceability and recall efficiency [23]; process efficiency, e.g., in sustainable supply chain management [13], smart manufacturing [14], water management [26]; efficient resource allocation and use [41]; reduced transaction delays [8]; increased efficiency in trade contracts and harmonization of conflicting objectives [8].

Industrial sustainability: enabling secure and reliable manufacturing systems with automated workflows and efficient operations [4].

New and inclusive financial services, financial inclusion of SMEs etc. e.g., microfinance or remittance for rural farmers [43], smart contractbased financial loan management for inclusion of SMEs [42].

New businesses models: support of sharing economy and circular economy [5][16]; boosting local economy, e.g., based on recovered solid waste [16]; extended revenue streams and financing modes [14].

\section{Environmental impact:}

Improved measurability and awareness of the environmental impact, and enhanced capacities for climate actions, e.g., track carbon footprints and environmental impacts [26], facilitate impact assessment and evaluation [26][41].

Improved monitoring and protection of sustainable use of natural resources and ecosystems, e.g., monitoring terrestrial [23][42] and oceanic ecosystems [13][41].

Improved resource efficiency and waste reduction: recycle and management [5]; circular economy enabler [14]; reduced food waste [11][37].

Reduction of pollution and environmental degradation: energy saving as a result of faster tracking and less paperwork [8]; fossil fuel usage and emission reduction due to better and efficient planning [8]

\section{Social impact:}

A secure and trustworthy infrastructure: secure systems for healthcare [16], energy [6], transport [28], supply chain management [5][13], manufacturing [7][14].

A tool for fighting against poverty [43]: social currency [43]; assistance in humanitarian aids [6]; fairer distribution of value [16].

\section{Awareness-raising and promotion of transition to sustainable} practices: improved awareness of environmental impacts [16]; engaging and motivating users / the public [13][28].

Enhanced trust and collaboration [8]: enhanced multi-stakeholder partnerships [37]; enhanced collaboration for autonomous agents [16]; enhanced trust in low-trust environment [28]; improved interchain coordination of IT outsourcing [40].

Fraud and corruption prevention: monitoring and ensuring human rights, fair trade and fair working practices [8]; potential to end unethical and illegal practices, e.g., slavery and Illegal, Unreported and Unregulated (IUU) fishing [13][41]; monitoring and overseeing sustainable conditions and regulatory policies [8]; implementing and managing corrective activities [44]; ensuring fair pricing [42].

${ }^{4}$ We give only one or two reference papers for each code in this overview table. For details, please refer to the description in Section IV.A.1.
Improved access to affordable and reliable resources: facilitating secure, reliable and efficient energy trading in energy systems [6][26].

Improved product safety, quality and traceability: ensuring product (food, drink, drug, etc.) provenance and quality [28][41]; anticounterfeiting [41]; traceability for sustainable agriculture [37], sustainable supply chain (medical, food, agri-food, etc.) [12]

Improved road traffic safety and sustainability [15][16][28]: improved road traffic safety; reduced congestion; reduced energy consumption and pollution.

Improved social inclusion and equality [44]: inclusions of low-income marginalized or restricted-market groups.

\section{Governmental impact:}

Collaborative urban/participatory decision making [16]: facilitating citizen engagement and democratization.

Smart administration and governance [4][16]: enhanced e-voting, eresidency, taxation, government document sharing, and so on.

Legal and regulatory impact:

Automatic compliance to regulatory and standards requirements: automatic verification and enforcement of compliance to regulations with auditable data and smart contracts [8][41].

Catalyzing development of policy and regulations [37]: facilitated determination and shaping of rules and governance norms at various levels (transport, logistics, supply chains) [8].

Proof of ownership and intellectual properties and digital rights management [16]: avoidance of double registration of properties [26], immutable and auditable certificates of learning achievements [4].

The blockchain's negative impacts on sustainability are summarized in Table 3 . The negative sustainability impacts are mainly due to the high energy consumption of using the PoW consensus algorithm and possible high investment to develop and operate blockchain-based systems.

TABLE 3 THEMATIC OVERVIEW OF BLOCKCHAIN'S POTENTIAL NEGATIVE IMPACTS ON SUSTAINABILITY ${ }^{5}$

Category and codes of negative impacts on sustainability

Economic impact:

High infrastructure investment and implementation cost [8][41] expensive to operate the blockchain-based system.

Environmental impact:

High carbon footprints and greenhouse gas (GHG) emissions [28]:

PoW consumes high energy.

Wasted resources [3][43]: PoW consumes high energy.

Social impact:

Job losses and job reskilling, e.g., due to the removal of intermediaries

[9].

Social inequality: not affordable for developing or underdeveloped countries, SMEs, smallholder farmers [9][43].

\section{B. THE RESULTS OF RQ2}

In RQ2, we tried to identify the key drivers and barriers to adopting blockchain technology in practice to satisfy SDG goals. The drivers are factors that motivate, enable, and facilitate the adoption of blockchain, for example, related to benefits that blockchain can bring about, strengths of the blockchain-based approaches over the traditional approaches, and opportunities to solve domain-specific challenges and needs. The barriers are factors that hinder the adoption of blockchains, such as challenges, threats and weaknesses related to the technology or its application to the domain.

${ }^{5}$ We give only one or two reference papers for each code in this overview table. For details, please refer to the description in Section IV.A.2. 
We followed the approach in [5] and classified the drivers and barriers into four high-level themes: intra-organizational (related to internal activities of organizations), inter-organizational (related to the relationship and collaboration with partners), technical and system-related (related to the blockchain technology itself or the blockchain-based systems), and external (related to external stakeholders, industries, institutions and governments that are not directly affected by the organizations' activities).

\section{1) DRIVERS TO ADOPTING BLOCKCHAIN}

\section{1) Intra-organizational drivers}

- Upper-level management support [14]. Blockchain is an emergent technology and needs upper-level management support to be adopted.

- Key resources transparency [14]. Blockchain applications need more visible, traceable, and dis-intermediary access to key resources.

- Decentralized decision within an organization [14]. A decentralized decision mechanism will ease the adaption of a blockchain-based application.

- Automated business processes and handling [8][13][39][41]. Having real-time information sharing, verification, and compliant checking could smoothen the use of smart contracts.

1.2) Inter-organizational drivers

- Transparency, visibility and real-time information sharing among different parties [8][11][12][14][15][16] [28][29][37][39][40][41][42]. Transparency in value chains and amongst stakeholders and timely sharing of data enables blockchain-based applications.

- Computational trust across multiple entities [9][14]. "Trust is the most influential factor driving interest in the blockchain within supply chain management" [9], where computational trust refers to "the reliability of the information provided by trade partners, or the safety and security of the data managed by a central authority" [9]. Blockchain applications need high-quality data inputs to deliver values.

- Decentralization across organizations [28]. Many blockchain-based applications need efficient information exchange and transaction, high data availability, decentralized decision, and self-organized collaboration.

1.3) Technical and system-related drivers

- Security and privacy mechanisms to address cybersecurity threats $[7][8][14][15][16][28][26][36][42]$. Blockchain technology must provide good security and privacy assurance mechanism and algorithms.

- Functions that can be implemented using smart contracts [8][9][37][42]. Smart contracts enable automation and self-execution of predefined and mutually agreed contractual conditions.

- Transparency and accountability (immutability) of recorded data [8][37][44]. Blockchain's feature to provide transparent and trustworthy data address many SDGs challenges.

- Tamper-proof and finer-granular traceability [7][8] [13][14][26][28][29][37][39][41]. Greater transparency and efficiency in blockchain-based traceability motivate people to use blockchain for improving sustainability tracking system.

- Decentralized architecture and governance [15]. Blockchain's decentralized architecture means high network resilience and no single point of failure, enabling many SDG applications.

- Digital certification, verifiable digital documents, and indicator measurements for assessing indicators of sustainability and quality [13][41]. This provides the possibility to verify sustainability with meaningful and quantifiable indicators.

- Cryptocurrency, social currency and financial services (microfinance etc.) [3][9][43]. This enables and supports many blockchain-based applications.

- Possibility to be combined with disruptive technologies (IoT, Big data, AI, etc.) [8] [37]. Combing blockchain and disruptive technologies improves the applicability of using blockchain in different domains.

- Addressing challenges due to the increase in smart and connected devices [26][28][39]. Blockchain is a communication technology with secure and decentralized architecture and offers secure solutions which traditional cyber-security approaches cannot solve.

1.4) External drivers

- $\quad$ Policy and regulation support [36]. It is necessary to have favorable policies for blockchain adoption, such as the requirements supporting the development of blockchain applications in distributed PV industry from a policy perspective.

- Regulatory and standards requirements related to product quality, public safety and security $[5][8][9][16][23][28][37][38][41][42]$. This is related to, e.g., medicine transportation and storage requirements from environmental regulations and rules, requirements related to food and medicine safety, water and waste management.

- Consumers' increasing concern about product provenance (i.e., origin) and demands on sustainable products and practices [5][14][23][28][37][38][41][42]. Increasing expectations on traceability leads to higher demands of using blockchain-based applications.

- The increasing social awareness on sustainability [29][36][38][42]. This puts higher demands on using blockchain to get more real-time and trustworthy information related to environmental protection and sustainable practices.

\section{2) BARRIERS TO ADOPTING BLOCKCHAIN}

\section{1) Intra-organizational barriers}

- Investment in infrastructure and additional resources [5][8][13][14][23][28][37][41][43]. Implementing blockchain-based application requires additional implementation cost, hardware, and software upgrading.

- Lack of knowledge and expertise [2][5][8][9][13][15] [23][28][37][39][43]. Insufficient knowledge may lead to exaggerated belief in blockchain and misinformation regarding blockchains, such as associating Bitcoin with fraud and illegality. Lack of understanding of blockchain potential can significantly impact stakeholders' attitudes and their willingness to change. 
- Lack of management awareness and commitment $[5][8][13][14]$. This holds back transitioning to more sustainable practices using blockchain-based applications.

- Lack of new organizational policies regarding the use of blockchain technology [5][8][13]. Blockchain adoption may change or transform existing organizational culture or hierarchy. New policies need to be defined regarding the new roles, responsibilities, and expertise for the transition.

- Stakeholders' hesitation and resistance to change [5] $[8][9][13][14][15][23][28][39]$. This can be due to skepticism towards the transparency of blockchain, doubt or resistance to the changes in organizational culture or hierarchy resulting from the transition, reluctance to change to new systems due to inertia of legacy systems, fear of losing revenue models, intermediaries' fear of being removed from the value chain.

2.2) Inter-organizational barriers

- Organizational and cultural differences [5][13][28]. The differences can lead to communication challenges.

- Unwillingness to share valued information [5][8][9] [13]. This can be caused by the concern of reduced privacy or information assumed to be a competitive advantage.

- Lack of policy and robust rules regarding information sharing or addressing lost or stolen data [5][8][13][28]. Missing such support can affect the collaboration and adaption of blockchain.

- Lack of customers' awareness and intention to contribute to sustainability [5][13][14][23]. People may not understand the benefits of green certification schemes and have a low willingness to pay more for sustainable products or products produced with greater transparency.

- Interest conflicts/ Lack of effective collaboration [5][8] [13][14][15][37]. Different stakeholders have different needs, requirements, and premises. There is a lack of collaborative mindset and a lack of effective collaboration mechanisms among stakeholders with conflicting operational goals and priorities.

- $\quad$ Lack of central authority [8][13][28]. This leads to a lack of trust and "lower confidence about the effectiveness of a trustless distributed paradigm" [8].

- Network effect [8][9][15][37][41]. This is related to the required critical mass of adoption and technology diffusion.

2.3) Technical and system-related barriers

- Access limitation to the required technology, tools, and infrastructure [5][13][23][41]. Internet connectivity is a challenge to rural areas or open sea with no or limited access to broadband Internet.

- Immature technology in an early development phase $[2][8][13][15][28][39]$. The immaturity leads to technological vulnerabilities and the perception of insecurity or unreliability, impeding stakeholders' readiness for adoption. There are a number of technical challenges to be tackled, e.g., related to resource intensive and inefficient consensus algorithms [3][7][14] [23][39][43]; energy intensiveness for processing, key algorithms and computations within the blockchain [3] [7][8][23][39][43]; scalability and performance challenges $[2][3][6][7][8][11][13][14][15][16][23][28][37][39][43]$.
- $\quad$ Negative effect of immutability regarding erroneous data [5][9][13][28]. Mistakes are irreversible and may increase transaction costs.

- Lack of new business models, standard tools, methods, best practices and indicators [5][8][13][14]. This can hinder implementation and measurement of new solutions and sustainability practices.

- Cyber-security challenges [3][5][9][11][14][15]. Although blockchain-based application is more secure than some IT technologies, there are still many blockchainrelated cyber-attacks to be addressed.

- Reduced privacy due to transparency [2][3][7] [8][14][23][39]. Blockchain technologies still have many data privacy-related challenges to be addressed.

- Lack of consensus and standards leads to interoperability issues [5][8][9][11][13][14][15][23]. Standards are needed to guarantee the interoperability between blockchains and facilitate blockchain's integration with third-party or legacy systems. This hinders cooperation.

- Risks related to raw data manipulation, human errors, compromised data users and physical manipulative activities $\quad[3][5][6][7][8][9][13][14][15][28][37][41]$. Input data quality affects transparency and accountability. Blockchain ensures cyber-security, data immutability and integrity, but it is challenging to guarantee the quality and correctness of the input information and ensure that the digital layer (data) corresponds to the physical layer (assets represented by the blockchain).

\section{4) External barriers}

- Lack of or unclear governmental policies and regulations to guide and support sustainable and safe practice $[2][3][5][8][11][13][15][28][37][39]$. This is related to regulatory uncertainty due to the existence of several regulatory environments with various rules. For example, the adoption of some aspects of smart contracts potentially being overregulated or considered illegal [8][39].

- Lack of external stakeholders' involvement. This is related to missing ethical and safe practices and the promotion of blockchain for sustainable value creation [5][13][28].

- Market competition and demand uncertainty for sustainable products [5][13]. The competition and unpredictable customer behavior make it uncertain if the investment in sustainable practices and new technology will be paid back.

- Lack of rewards and encouragement programs associated with the application of blockchain technology [5][13]. People are skeptical of giving financial incentives to data validators in the blockchain-based system because ethical concerns reduce the opportunities to use well-established blockchain technologies.

- Implementation of blockchain-based solutions in global supply chains is a complex task [9][41]. This is because it has to conform to various laws, regulations and institutions.

\section{THE RESULTS OF RQ3}

This section pertains to the research gaps and directions required to avoid the barriers to blockchain adaption and their potential impacts on the SDGs. 
1) ADDRESSING BLOCKCHAIN ADOPTION BARRIERS Privacy protection and information sharing governance. Regarding the barrier related to an unwillingness to share valued information, blockchain's transparency (data is open to all participants) raises concerns about reduced privacy and the risk of losing business secrets. Privacy applications have been proposed to protect personal data against cyber-attacks in healthcare and voting systems [28][39], for example, by improving the security of privacy-sensitive data. [54] proposed a system utilizing blockchain to allow sharing of user data with privacy guaranteed through cryptography. However, in addition to such technological mechanisms, the ethical and legal implications and guidelines and best practices on information sharing should be considered. For example, people shall consider "whether, which and how personal data is being used, how to guarantee controls concerning data dissemination, analysis, and storage duration, as well as identity registries and where personally identifiable information is processed" [55]. Similar principles and considerations apply to the protection of business secrets as well. For instance, solid rules on information sharing for effective collaboration among partners should be defined.

To ensure smooth information exchange and facilitate blockchain adoption, a governance framework needs to be defined regarding which type of blockchain to choose (e.g., private, public and consortium), what sustainability information shall be stored on blockchain, which information can be shared publicly and which should be kept private to safeguard privacy and business secrets, who and how to collect the data and to upload them on blockchain, who has the ownership of the data stored on blockchain and the IP ownership associated with the data, who should be responsible for data input and provision, and how to use the data [9][56]. When clear rules are defined, smart contracts may be exploited to set conditions on how and by whom the data will be accessed and analyzed to enforce customized access levels and views associated with different users.

Legal frameworks and standards. Lacking regulations and standards represents uncertainty and risks for companies and holds back their transitioning to blockchain technology. For example, there is uncertainty regarding smart contracts legal validity and enforcement mechanisms when disputes arise [9]. A legal framework is necessary for blockchain to reach its full potential. Appropriate legal framework and policies may be defined regarding regulations to constrain the data manipulations, such as:

- Using certificates and regular checks to ensure raw data authenticity,

- Traceability or regulatory monitoring to encourage companies to take responsibility for the products and provide authentic information,

- $\quad$ Regulations for preventing fraud and money laundering activities,

- Policies supporting data sharing between parties from the law enforcement against some cyber risks,

- The criteria to guarantee the legal validity and enforceability of smart contracts [9].

To address the limitations of blockchain technology. Fully public blockchains with a high degree of computerization (e.g., using PoW) are being criticized for the high demand on resource and energy and high carbon footprint, compromising outcomes on SDGs 7 and 13 in particular. It is essential to investigate mechanisms to make the blockchain technology "greener", e.g., through more efficient consensus algorithms.

More affordable and inclusive technologies. Blockchain may be not affordable for developing or underdeveloped countries and for SMEs or small farmers in rural areas due to its high computerization and infrastructure requirements. It is important to explore use cases in developing countries and solutions that can scale and address practical issues related to deployment in settings with limited Internet access and electricity [27]. For example, blockchain technology requires Internet connection to function, which may be challenging in rural areas or the open sea. Mechanisms should be investigated to allow blockchain to work in environments with no or unstable Internet connections. Moreover, to gain insights into the implementation dynamics and facilitate blockchain adoption on various types of organizations, a comparison between blockchain drivers and barriers with different organization sizes (SMEs vs large corporations) could be studied [14]. Furthermore, it is essential to make blockchain "SME friendly", meaning "easy to use, easy to deploy with low initial costs" [37].

Software engineering tools and methods. Further research is needed to tackle the barrier regarding the absence of standard tools and methods for implementing blockchain applications, particularly software engineering methodology and framework for developing blockchain-based systems. [57] pointed out some software engineering research directions, e.g., user involvement in defining and eliciting software requirements, flexible architectures, verification of the functional and non-functional system properties, and empirical evaluation methods and criteria. [58] and [59] reported research and experience regarding requirement engineering to eliciting user needs and system requirements for blockchain-based energy demand-response systems and understanding the values in P2P energy-trading systems. More research of this kind is desirable to bridge the research gap regarding software engineering theory and practices for blockchain implementation to achieve SDGs. [9] also suggested research direction on design science-based design and the development of generic actions, processes, and systems operationalized in various contexts.

Empirical studies on blockchain technology sustainability. Regarding the sustainability of blockchain technology, PoW has been criticized for its negative impacts on energy intensiveness and environmental footprint. However, other blockchain protocols like PoS and BPFT are more efficient and consume less energy. Nevertheless, it is questionable whether blockchain consumes more energy than other technology. This may depend on the metrics to measure the sustainability impact. A benchmark on software sustainability is desirable to compare the sustainability of the software technologies and their impacts on SDGs.

\section{2) ADDRESSING IMPACTS ON SDGS}

Meaningful and quantifiable sustainability indicators. Blockchain-empowered traceability can monitor activities in various contexts and verify sustainability indicators in a more meaningful and quantifiable way [13]. However, the lack of standard indicators and methods hinders the effective monitoring and verification of sustainability practices. An 
indicator framework with definitions of the sustainability measures is needed to exploit this quantifiable capability.

Evidence-based knowledge on large-scale and long-term effects. We observed that negative impacts on sustainability are not much touched upon in the surveyed papers. Most papers addressed challenges, barriers, problems, etc., related to the adoption of blockchain but not related to negative effects on sustainability. Therefore, we were not able to link negative impacts to most SDG targets. This may be due to the current state of blockchain as an emerging technology since most of the discussion of blockchain technology is theoretical or hypothetical, without much reference to use cases and experience from real deployment. Moreover, the few real implementations have only been introduced on a small scale and recently. For instance, [28] has outlined the level of implementation of blockchain-based systems in transportation mentioned in a number of research papers, where 14 of the 20 proposals are at a concept level (including simulations), with only 3 proof of concepts and 3 real implementations. Based on an analysis of the readiness of blockchain technology in smart grid, [6] pointed out that the application is still immature and needs to study and realize "more studies, real experiments, and industrial utilizations." [60] pointed out the lack of empirical studies on blockchain for sustainable development, and [61] evidenced that the SDG focus on sustainable development has been overlooked in existing Information Systems (IS) research and IS studies are scarce in sustainability in general. The analysis in [61] illustrated that existing IS empirical studies covered only 9 out of the 17 SDGs. [57] also indicated a lack of experience papers and evaluation studies, especially using empirical software engineering approaches.

In other words, there is little evidence-based knowledge on blockchain application, apart from within the financial sector. In particular, there is a lack of empirical evidence on the long-term impact of large-scale applications and no investigation of the potential negative impacts of blockchain on sustainability in various contexts. There is also limited documentation on the initiatives and experimentations, especially regarding their negative impacts and limitations.

Moreover, the current literature on impacts is mainly showcasing or theoretical analysis, not based on measurements. A well-known example is the blockchain traceability for US mangos, which can track the origin of US mangoes in $2.2 \mathrm{~s}$, instead of about seven days that it used to be with non-blockchain technologies [9][37][41]. However, there is no comprehensive evaluation of its impacts, e.g., from economic, social, and environmental aspects or SDGs viewpoint. Large scale and longterm measurements are needed to give evidence of the impacts. As such, there is a need for frameworks for comprehensive evaluation of the outcomes with well-defined metrics and methodology. This will facilitate critical reflection on the current investments and experimentations and the empirical evidence concerning the long-term effects, unanticipated and detrimental impacts, as well as limitations of blockchain in these contexts.

Furthermore, research on ethical issues associated with blockchain and its applications is also essential for preventing the potential negative consequences of blockchain technology. [62] has described a roadmap to further research on the ethics of blockchain. The legal and ethical implications of SDGs should be considered.
Finally, a reference framework is needed to support stakeholders to "make more informed decisions as to whether to invest in the development of the technology, as well as how to design its architecture to meet their demands" [55]. Based on lessons learned and experience from previous initiatives and experimentations as well as the empirical evidence on the impacts on SDGs, this framework should comprise, among others, best practices and guidelines on the selection of relevant blockchain technology to meet SDGs, patterns or anti-patterns for the design and implementation as well as examples and use cases.

\section{DISCUSSION}

\section{A. COMPARISON WITH RELATED WORK}

[33] presents an assessment of the potential impacts that artificial intelligence may exert on achieving the SDGs, based on a consensus-based expert elicitation process. The method was also applied by previous studies of mapping SDGs interlinkages [34][35].

Study [57] is a systematic mapping study that provides stateof-the-art research on blockchain and sustainability, focusing on identifying software engineering aspects of blockchain in smart grids and supply chain management. The research was considered in the context of UN SDGs 2, 7 and 13 specifically.

[53] reflects on the potential socially and environmentally beneficial use cases and outcomes framed in the UN SDGs. However, it did not provide explicit interlinkage between blockchain and SDGs.

The workshop report [55] presents the results of the discussions in the Blockchain4SDGs interdisciplinary workshop held in December 2017, exploring the implications of blockchain from both the possibilities and limitations in the field of development and humanitarian action and how to use blockchain technology (BCT) to address SDGs. Mainly from humanitarian and development viewpoints, the report discussed BCT's practical and ethical considerations in blockchain mining, supply chains, sharing economy, innovation in governance, and financial inclusion.

Based on a review of empirical studies in the Information System (IS) field, [61] mapped research on blockchain and sustainable development using the 17 UN SDGs as a classification tool and outlined a research agenda in the IS field. They provided one example blockchain application for each of the $17 \mathrm{SDG}$, which evidenced that initiatives using blockchain for sustainable development cover all aspects of the SDGs, similar to what we have depicted in our findings. However, their work did not consider the potential positive or negative impacts on SDGs, not to mention the SDG targets or BCT adoption for sustainable development.

Existing literature reviews usually investigate blockchain's role on sustainability for specific application areas, e.g., sustainable supply chain management [13], smart cities [4], sustainable manufacturing [7][14]. Only a few of them touched on several SDGs, e.g., [13]. None of them documented connections between blockchain and the UN SDGs as a whole, not to mention the detailed targets in each SDG. Our work bridges this research gap, providing an extensive mapping of interlinkage at the target level and looking at SDGs as a coherent system. Furthermore, we do not limit our discussion to a specific 
domain or application area but attempt to cover all potential areas from the existing literature.

\section{B. IMPLICATIONS TO ACADEMIA AND PRACTITIONERS}

\section{1) FOR RESEARCHERS}

Our work investigates the state-of-the-art research and practices for blockchain and sustainability and contributes to the body of knowledge for blockchain's role in meeting the SDGs. Some SDGs have more use cases and applications, while others may need more research, e.g., regarding innovative applications and their impacts. For researchers, our work offers a systematic approach to understanding the blockchain potential against the principles of SDGs and opportunities to identify the unexplored SDGs areas, recognizing blockchain's immense potential impacts and capabilities.

Blockchain has a great potential to empower numerous generic applications. When designing new applications and systems, the potential negative impacts and adoption barriers should not be neglected. Research is needed to mitigate them. Results of RQ3 suggest some research directions in this regard.

\section{2) FOR COMPANIES USING BLOCKCHAIN}

Much work is about using BCT to improve conditions for companies, e.g., for sustainable production. Blockchain can enable new services and applications and enhance or transform existing processes, systems, or services. A multitude of use cases for innovations is available in various domains. Blockchain is still in a growth stage, and significant progress and new opportunities can be expected shortly. The analysis of this paper may shed light on new directions and solutions that would assist companies and customers integrate their needs through blockchain.

Although it looks promising that blockchain adoption can enhance sustainability and has enormous potential to impact SDGs positively, blockchain may not be suitable for all contexts and needs. Many alternative blockchain technologies exist, and there is no "one-size-fits-all" solution. Before implementing a blockchain, organizations need to carefully evaluate their business needs and usage scenarios and decide whether blockchain is needed and how it can be used, for example, which blockchain technology or architecture (permissionless, permissioned or private blockchain) should be chosen.

Some well-known decision trees with questions that help evaluate the applicability of blockchain technology are available in the literature $[6][11][63][64][65][66][67]$. [55] suggested four evaluation criteria for determining the suitability of BCT for use within the development and humanitarian affairs. [15] presented a flow chart for deciding the applicability of blockchain from business management and cyber-security standpoint. It also noted that traditional databases or ledgers might be a better solution for daily operations in a trustful scenario or when stakeholders can trade directly. However, [16] highlighted inconsistencies between the reported use cases and the wellknown decision rules. Even if some decision rules are not passed, the blockchain technology or a specific type of blockchain can still be used in a concrete use case because the application may focus on exploiting different features that blockchain offers. There are different design choices for implementing the same function. A more systematic analysis like the one suggested in [16] may help.
[41] claimed that blockchain is an attractive and cost-effective option to solve a messaging problem other than a database problem. It argued that blockchain application is more appropriate in the supply chain than in auto and tech industries, and security concerns in the supply chain favor permissioned /private blockchain. It also analyzed the advantage of adoption on the supply chain than on the finance domain.

There are also recommendations on how to select appropriate technologies to overcome specific barriers. For example, [47] identified solutions for the challenges of blockchain technology in agri-food value chain management. Some of them are also applicable to other domains and application cases as well.

Our work offers companies adopting blockchain technology a better understanding of blockchain, its potential impacts on SDGs and possible adoption barriers, and reminds them of the importance of adequately evaluating its suitability and applicability for their needs. In particular, the knowledge of the BCT and its sustainability advantages for various fields and the awareness of the intra-organizational and inter-organizational barriers can lift the awareness and commitment of the management, incentivize the creation of new organizational policies and other aspects needed for a favorable environment for this transition.

\section{3) FOR POLICYMAKERS}

For policymakers, our work provides insight and understanding of the technology and its impacts on SDGs, and the legal and regulatory barriers for blockchain adoption, facilitating the establishment of the needed supportive legislation and governance framework.

\section{THREATS TO VALIDITY}

Our work is a tertiary review that is based on the systematic review of the reviews on the selected topic. Thus, the results are limited by the scope of the included papers. There may be bias in selecting papers and the documented evidence in the included papers may not be exhaustive. As the literature seldom explicitly provided the linkage between blockchain and SDGs, specifically at the SDG targets level, we have created the mapping based on our understanding of the impact and the SDGs. The results may be biased or limited by our knowledge and understanding. Nevertheless, as described in the methodology section, we have tried to mitigate this limitation through consulting literature on SDGs, adopting the expert consensus method, verifying the results by at least two authors in the process, and reviewing the mappings several iterations.

In Figure 2, some SDG targets are not marked with positive or negative impacts, as we have not found evidence of potential impacts from the literature we reviewed. However, this does not mean that there is no relationship between blockchain and the remaining SDG targets. Additional literature search and future research may indicate further interlinkage between blockchain and SDGs not mapped in Figure 2.

\section{CONCLUSION AND FUTURE WORK}

Blockchain is a disruptive technology and a driver for social changes. Combined with other technologies, like AI, big data and IoT, blockchain has a great potential to empower numerous innovative applications and provide technological improvement or enhancement to overcome limitations or domain challenges. Therefore, it can act as a catalyst to achieve potentially all SDG targets. It has exhibited great potential to 
promote sustainable practices and help organizations, governments, and institutions achieve SDGs.

This tertiary review, built upon existing systematic reviews on the relationship between blockchain and sustainability, has investigated the potential positive and negative impacts on SDGs that blockchain may bring about. Positive impacts on all 17 SDGs with direct impacts on 73 SDG targets have been identified from the surveyed papers. On the other hand, very few negative impacts on SDGs and their targets have been listed in the current literature. However, most blockchain applications are prototype and new deployment, or even only at a conceptual level. There is a lack of real-life large-scale applications and long-term effects to be able to conclude.

Based on thematic analysis from identified systematic reviews, this study presents a systematic overview of drivers and barriers to blockchain adoption for sustainable development, categorized by intra-organizational, inter-organizational, technical and system-related, and external aspects. As there is no one-size-fits-all solution, organizations adopting blockchain must carefully evaluate its applicability based on their operational and business needs and usage scenarios.

Blockchain is still an immature technology. Its deployment is in its early stages and has been largely experimental. There is a lack of evidence-based knowledge on blockchain application to areas outside the financial sector. Future research is needed on empirical studies regarding large-scale deployment and longterm impacts on sustainability. It also calls for further research on standard tools and methods for implementing blockchain solutions that can meet SDGs.

\section{APPENDIX}

TABLE A-1. SURVEYED PAPERS WITH EVIDENCE ON BLOCKCHAIN'S POTENTIAL

\begin{tabular}{|c|c|}
\hline \multicolumn{2}{|r|}{ POSITIVE IMPACTS ON SDGS. } \\
\hline SDG & Reference paper \\
\hline SDG 1 - No poverty & {$[6],[8],[9],[13],[36],[41],[43],[44]$} \\
\hline SDG 2 - Zero hunger & $\begin{array}{l}{[5],[6],[9],[11],[12],[13],[37],[38],[28],} \\
{[39],[41],[42],[43],[44]}\end{array}$ \\
\hline $\begin{array}{l}\text { SDG } 3 \text { - Good health } \\
\text { and well-being }\end{array}$ & $\begin{array}{l}{[4],[9],[11],[12],[13],[16],[28],[37],[39],} \\
{[41],[43]}\end{array}$ \\
\hline $\begin{array}{l}\text { SDG } 4 \text { - Quality } \\
\text { education }\end{array}$ & {$[4],[13],[16]$} \\
\hline $\begin{array}{l}\text { SDG } 5 \text { - Gender } \\
\text { equality }\end{array}$ & [44] \\
\hline $\begin{array}{l}\text { SDG } 6 \text { - Clean water } \\
\text { and sanitation }\end{array}$ & {$[16],[26]$} \\
\hline $\begin{array}{l}\text { SDG } 7 \text { - Affordable } \\
\text { and clean energy }\end{array}$ & {$[4],[6],[16],[26],[28],[36],[42],[43],[44]$} \\
\hline $\begin{array}{l}\text { SDG } 8 \text { - Decent work } \\
\text { and economic growth }\end{array}$ & $\begin{array}{l}{[8],[9],[13],[14],[15],[16],[23],[28],[29],} \\
{[39],[41],[42],[43],[44]}\end{array}$ \\
\hline $\begin{array}{l}\text { SDG } 9 \text { - Industry, } \\
\text { Innovation and } \\
\text { Infrastructure }\end{array}$ & $\begin{array}{l}{[4],[7],[8],[9],[13],[14],[15],[16],[36],} \\
{[39],[41],[42]}\end{array}$ \\
\hline $\begin{array}{l}\text { SDG } 10 \text { - Reduced } \\
\text { inequalities }\end{array}$ & {$[9],[13],[14],[16],[26],[41],[42],[43],[44]$} \\
\hline $\begin{array}{l}\text { SDG } 11 \text { - Sustainable } \\
\text { cities and communities }\end{array}$ & {$[4],[6],[13],[14],[15],[16],[26],[28]$} \\
\hline $\begin{array}{l}\text { SDG } 12 \text { - Responsible } \\
\text { consumption and } \\
\text { production }\end{array}$ & $\begin{array}{l}{[4],[5],[7],[8],[9],[11],[12],[13],[14],[16],} \\
{[23],[26],[28],[29],[37],[38],[39],[41],} \\
{[42],[44]}\end{array}$ \\
\hline $\begin{array}{l}\text { SDG } 13 \text { - Climate } \\
\text { action }\end{array}$ & $\begin{array}{l}{[2],[8],[13],[16],[26],[28],[29],[37],[38],} \\
{[42],[44]}\end{array}$ \\
\hline $\begin{array}{l}\text { SDG } 14 \text { - Life beneath } \\
\text { water }\end{array}$ & {$[13],[41]$} \\
\hline $\begin{array}{l}\text { SDG } 15 \text { - - Life on } \\
\text { land }\end{array}$ & {$[13],[16],[23],[42]$} \\
\hline $\begin{array}{l}\text { SDG } 16 \text { - Peace, } \\
\text { justice and strong } \\
\text { institutions }\end{array}$ & $\begin{array}{l}{[4],[5],[8],[9],[13],[15],[16],[26],[29],} \\
{[39],[41],[43],[44]}\end{array}$ \\
\hline
\end{tabular}

SDG 17 - Partnerships $\quad$ [7], [8], [9], [13], [14], [16], [23], [28], [29], for the goals $[37],[38],[39],[40],[41],[44]$

TABLE A-2. SURVEYED PAPERS WITH EVIDENCE ON BLOCKCHAIN'S POTENTIAL NEGATIVE IMPACTS ON SDGS. ONLY THE SDGS THAT BLOCKCHAIN HAS NEGATIVE IMPACT ON ARE INCLUDED.

\begin{tabular}{|l|l|}
\hline \multicolumn{1}{|c|}{ SDG } & \multicolumn{1}{c|}{ Reference paper } \\
\hline SDG 2-Zero hunger & {$[9],[41],[43]$} \\
\hline $\begin{array}{l}\text { SDG 7 - Affordable } \\
\text { and clean energy }\end{array}$ & {$[3],[8],[15],[28],[43],[45]$} \\
\hline $\begin{array}{l}\text { SDG 8 - Decent work } \\
\text { and economic growth }\end{array}$ & {$[3],[9],[41],[43],[45]$} \\
\hline $\begin{array}{l}\text { SDG 9-Industry, } \\
\text { Innovation and } \\
\text { Infrastructure }\end{array}$ & {$[9],[41],[43]$} \\
\hline $\begin{array}{l}\text { SDG 10- Reduced } \\
\text { inequalities }\end{array}$ & {$[9],[41],[43]$} \\
\hline $\begin{array}{l}\text { SDG 12- } \\
\text { Responsible } \\
\text { consumption and } \\
\text { production }\end{array}$ & {$[3],[43],[45]$} \\
\hline $\begin{array}{l}\text { SDG 13-Climate } \\
\text { action }\end{array}$ & {$[28],[43],[45]$} \\
\hline $\begin{array}{l}\text { SDG 16-Peace, } \\
\text { justice and strong } \\
\text { institutions }\end{array}$ & {$[3],[9],[43]$} \\
\hline
\end{tabular}

\section{ACKNOWLEDGMENT}

The authors would like to thank Prof. Letizia Jaccheri for her help in forming the paper.

\section{REFERENCES}

11] United Nations, "Transforming our World: The 2030 Agenda for Sustainable Development," United Nations, 2015. [Online]. Available: https://sustainabledevelopment.un.org/post2015/transformingourworld/p ublication

[2] Y. Lu, "Blockchain and the related issues: a review of current research topics," J. Manag. Anal., vol. 5, no. 4, pp. 231-255, 2018, doi: 10.1080/23270012.2018.1516523

[3] S. Fernandez-Vazquez, R. Rosillo, D. De La Fuente, and P. Priore, "Blockchain in FinTech: A mapping study," Sustain. Switz., vol. 11, no. 22, 2019, doi: 10.3390/su11226366.

[4] H. Treiblmaier, A. Rejeb, and A. Strebinger, "Blockchain as a Driver for Smart City Development: Application Fields and a Comprehensive Research Agenda," Smart Cities, vol. 3, no. 3, pp. 853-872, 2020, doi: 10.3390/smartcities3030044

[5] S. Saberi, M. Kouhizadeh, J. Sarkis, and L. Shen, "Blockchain technology and its relationships to sustainable supply chain management,” Int. J. Prod. Res., vol. 57, no. 7, pp. 2117-2135, Apr. 2019, doi: 10.1080/00207543.2018.1533261.

[6] A. S. Musleh, G. Yao, and S. M. Muyeen, "Blockchain Applications in Smart Grid-Review and Frameworks," IEEE Access, vol. 7, pp. 8674686757, 2019, doi: 10.1109/ACCESS.2019.2920682.

[7] ElMamy, S. B., H. Mrabet, H. Gharbi, A. Jemai, and D. Trentesaux. 2020 "A Survey on the Usage of Blockchain Technology for Cyber-Threats in the Context of Industry 4.0.” Sustainability (Switzerland) 12(21):1-19. doi: 10.3390/su12219179.

[8] M. Jović, E. Tijan, D. Žgaljić, and S. Aksentijević, "Improving maritime transport sustainability using blockchain-based information exchange," Sustain. Switz., vol. 12, no. 21, pp. 1-19, 2020, doi: $10.3390 / \mathrm{su} 12218866$

[9] Y. Wang, J. H. Han, and P. Beynon-Davies, "Understanding blockchain technology for future supply chains: a systematic literature review and research agenda," Supply Chain Manag. Int. J., vol. 24, no. 1, pp. 62-84, Jan. 2019, doi: 10.1108/SCM-03-2018-0148.

[10] S. Garcia-Torres, L. Albareda, M. Rey-Garcia, and S. Seuring, "Traceability for sustainability - literature review and conceptual framework," Supply Chain Manag. Int. J., vol. 24, no. 1, pp. 85-106, Jan. 2019, doi: 10.1108/SCM-04-2018-0152.

[11] H. Feng, X. Wang, Y. Duan, J. Zhang, and X. Zhang, "Applying blockchain technology to improve agri-food traceability: A review of development methods, benefits and challenges," J. Clean. Prod., vol. 260, 2020, doi: 10.1016/j.jclepro.2020.121031.

[12] J. Qian et al., "Food traceability system from governmental, corporate, and consumer perspectives in the European Union and China: A 
comparative review," Trends Food Sci. Technol., vol. 99, pp. 402-412, 2020, doi: 10.1016/j.tifs.2020.03.025.

[13] V. Paliwal, S. Chandra, and S. Sharma, "Blockchain technology for sustainable supply chain management: A systematic literature review and a classification framework," Sustain. Switz., vol. 12, no. 18, 2020, doi: $10.3390 / \mathrm{su} 12187638$

[14] J. Leng et al., "Blockchain-empowered sustainable manufacturing and product lifecycle management in industry 4.0: A survey," Renew. Sustain. Energy Rev., vol. 132, 2020, doi: 10.1016/j.rser.2020.110112.

[15] P. Fraga-Lamas and T. M. Fernández-Caramés, "A Review on Blockchain Technologies for an Advanced and Cyber-Resilient Automotive Industry," IEEE Access, vol. 7, pp. 17578-17598, 2019, doi: 10.1109/ACCESS.2019.2895302.

[16] C. Shen and F. Pena-Mora, "Blockchain for Cities-A Systematic Literature Review," IEEE Access, vol. 6, pp. 76787-76819, 2018, doi: 10.1109/ACCESS.2018.2880744.

[17] S. Jiang, K. Jakobsen, L. Jaccheri, and J. Li, "Blockchain and Sustainability: A Tertiary Study," in 2021 IEEE/ACM International Workshop on Body of Knowledge for Software Sustainability (BoKSS), Los Alamitos, CA, USA, Jun. 2021, pp. 7-8. doi: 10.1109/BoKSS52540.2021.00011.

[18] B. A. Kitchenham and S. Charters, "Guidelines for performing Systematic Literature Reviews in Software Engineering," Keele University, EBSE 2007-001, 2007. [Online]. Available: https://www.elsevier.com/_data/promis_misc/525444systematicreview sguide.pdf

[19] V. Braun and V. Clarke, "Using thematic analysis in psychology," Qual. Res. Psychol., vol. 3, no. 2, pp. 77-101, Jan. 2006, doi: 10.1191/1478088706qp063oa.

[20] J. Elkington, "ACCOUNTING FOR THE TRIPLE BOTTOM LINE," Meas. Bus. Excell., vol. 2, no. 3, pp. 18-22, Jan. 1998, doi: $10.1108 / \mathrm{eb025539.}$

[21] United Nations, "Report of the World Commission on Environment and Development: Our Common Future," United Nations, 1987. [Online]. Available:

https://sustainabledevelopment.un.org/content/documents/5987ourcommon-future.pdf

[22] UNDP, "What are the Sustainable Development Goals?," 2021. https://www.undp.org/sustainable-development-goals (accessed August 09, 2021).

[23] J. Astill et al., "Transparency in food supply chains: A review of enabling technology solutions," Trends Food Sci. Technol., vol. 91, pp. 240-247, 2019, doi: 10.1016/j.tifs.2019.07.024.

[24] M. S. Ferdous, M. J. M. Chowdhury, and M. A. Hoque, "A survey of consensus algorithms in public blockchain systems for cryptocurrencies," J. Netw. Comput. Appl., vol. 182, p. 103035, May 2021, doi: 10.1016/j.jnca.2021.103035

[25] B. Cao et al., "When Internet of Things Meets Blockchain: Challenges in Distributed Consensus," IEEE Netw., vol. 33, pp. 133-139, 2019.

[26] P. F. Wong, F. C. Chia, M. S. Kiu, and E. C. W. Lou, "The potential of integrating blockchain technology into smart sustainable city development," IOP Conf. Ser. Earth Environ. Sci., vol. 463, p. 012020 , Apr. 2020, doi: 10.1088/1755-1315/463/1/012020.

[27] J. Thomason, "Blockchain: an accelerator for women and children's health?," 2017.

[28] V. Astarita, V. P. Giofrè, G. Mirabelli, and V. Solina, "A Review of Blockchain-Based Systems in Transportation,” Inf. Switz., vol. 11, no. 1, 2020, doi: 10.3390/info11010021.

[29] L. P. Mahyuni, R. Adrian, G. S. Darma, N. N. K. Krisnawijaya, I. G. A. A. P. Dewi, and G. P. L. Permana, "Mapping the potentials of blockchain in improving supply chain performance," Cogent Bus. Manag., vol. 7, no. 1, 2020, doi: 10.1080/23311975.2020.1788329.

[30] Z. Zheng, S. Xie, H. Dai, X. Chen, and H. Wang, "An Overview of Blockchain Technology: Architecture, Consensus, and Future Trends," in 2017 IEEE International Congress on Big Data (BigData Congress), Jun. 2017, pp. 557-564. doi: 10.1109/BigDataCongress.2017.85.

[31] D. Puthal, N. Malik, S. P. Mohanty, E. Kougianos, and G. Das, "Everything You Wanted to Know About the Blockchain: Its Promise, Components, Processes, and Problems," IEEE Consum. Electron. Mag., vol. 7, no. 4, pp. 6-14, Jul. 2018, doi: 10.1109/MCE.2018.2816299.

[32] T. Ahram, A. Sargolzaei, S. Sargolzaei, J. Daniels, and B. Amaba, "Blockchain technology innovations," in 2017 IEEE Technology \& Engineering Management Conference (TEMSCON), Jun. 2017, pp. 137141. doi: 10.1109/TEMSCON.2017.7998367.

[33] R. Vinuesa et al., "The role of artificial intelligence in achieving the Sustainable Development Goals," Nat. Commun., vol. 11, no. 1, p. 233, Jan. 2020, doi: 10.1038/s41467-019-14108-y.
[34] F. Fuso Nerini et al., "Connecting climate action with other Sustainable Development Goals," Nat. Sustain., vol. 2, no. 8, pp. 674-680, Aug. 2019, doi: 10.1038/s41893-019-0334-y.

[35] F. Fuso Nerini et al., "Mapping synergies and trade-offs between energy and the Sustainable Development Goals," Nat. Energy, vol. 3, no. 1, pp 10-15, Jan. 2018, doi: 10.1038/s41560-017-0036-5.

[36] J. Hou, H. Wang, and P. Liu, "Applying the blockchain technology to promote the development of distributed photovoltaic in China," Int. J. Energy Res., vol. 42, no. 6, pp. 2050-2069, 2018, doi: 10.1002/er.3984.

[37] J. Duan, C. Zhang, Y. Gong, S. Brown, and Z. Li, "A content-analysis based literature review in blockchain adoption within food supply chain," Int. J. Environ. Res. Public. Health, vol. 17, no. 5, 2020, doi: 10.3390/ijerph17051784.

[38] S. S. Kamble, A. Gunasekaran, and S. A. Gawankar, "Achieving sustainable performance in a data-driven agriculture supply chain: A review for research and applications," Int. J. Prod. Econ., vol. 219, pp. 179-194, 2020, doi: 10.1016/j.ijpe.2019.05.022.

[39] E. Tijan, S. Aksentijević, K. Ivanić, and M. Jardas, "Blockchain technology implementation in logistics," Sustain. Switz., vol. 11, no. 4, 2019, doi: $10.3390 /$ su11041185.

[40] Malgorzata Pankowska, "Information Technology Outsourcing Chain: Literature Review and Implications for Development of Distributed Coordination," Sustainability, vol. 11, no. 5, p. 1460, Jan. 2019, doi: $10.3390 / \mathrm{su} 11051460$

[41] N. Kshetri, "1 Blockchain's roles in meeting key supply chain management objectives," Int. J. Inf. Manag., vol. 39, pp. 80-89, Apr. 2018, doi: 10.1016/j.ijinfomgt.2017.12.005.

42] C. H. Lim et al., "A review of industry 4.0 revolution potential in sustainable and renewable palm oil industry: HAZOP approach," Renew. Sustain. Energy Rev., vol. 135, p. 110223, Jan. 2021, doi: 10.1016/j.rser.2020.110223.

[43] P. Giungato, R. Rana, A. Tarabella, and C. Tricase, "Current trends in sustainability of bitcoins and related blockchain technology," Sustain. Switz., vol. 9, no. 12, 2017, doi: 10.3390/su9122214.

[44] J. Horner and P. Ryan, "Blockchain standards for sustainable development," J. ICT Stand., vol. 7, no. 3, pp. 225-247, 2019, doi: 10.13052/jicts2245-800X.733

[45] J. Truby, "Decarbonizing Bitcoin: Law and policy choices for reducing the energy consumption of Blockchain technologies and digital currencies," Energy Res. Soc. Sci., vol. 44, pp. 399-410, 2018, doi: 10.1016/j.erss.2018.06.009

[46] A. S. L. França, J. Amato Neto, R. F. Gonçalves, and C. M. V. B. Almeida, "Proposing the use of blockchain to improve the solid waste management in small municipalities," J. Clean. Prod., vol. 244, 2020, doi: 10.1016/j.jclepro.2019.118529.

[47] G. Zhao et al., "Blockchain technology in agri-food value chain management: A synthesis of applications, challenges and future research directions," Comput. Ind., vol. 109, pp. 83-99, Aug. 2019, doi: 10.1016/j.compind.2019.04.002.

[48] M. O. AlMuhairi, "Why COVID-19 makes a compelling case for the wider integration of blockchain," May 08, 2020 https://www.weforum.org/agenda/2020/05/why-covid-19-makes-acompelling-case-for-wider-integration-of-blockchain/ (accessed August 09, 2021)

[49] S. Sinclair, "Spanish Researchers Working to Curb Coronavirus Spread With Blockchain App," Apr. 17, 2020 https://finance.yahoo.com/news/spanish-researchers-working-curbcoronavirus-140007260.html (accessed August 09, 2021).

[50] E. M. Dogo, A. F. Salami, N. I. Nwulu, and C. O. Aigbavboa, "Blockchain and Internet of Things-Based Technologies for Intelligent Water Management System," in Artificial Intelligence in IoT, Springer, Cham., 2019, pp. 129-150. [Online]. Available: https://doi.org/10.1007/978-3-030-04110-6_7

[51] N. Kshetri, "Blockchain and sustainable supply chain management in developing countries,” Int. J. Inf. Manag., vol. 60, p. 102376, Oct. 2021 doi: 10.1016/j.ijinfomgt.2021.102376.

[52] L. Recuero Virto, "A preliminary assessment of the indicators for Sustainable Development Goal (SDG) 14 'Conserve and sustainably use the oceans, seas and marine resources for sustainable development,", Mar. Policy, vol. 98, pp. 47-57, Dec. 2018, doi: 10.1016/j.marpol.2018.08.036.

[53] R. Adams, B. Kewell, and G. Parry, "Blockchain for Good? Digital Ledger Technology and Sustainable Development Goals," in Handbook of Sustainability and Social Science Research, Springer International Publishing, 2018, pp. 127-140. [Online]. Available: https://doi.org/10.1007/978-3-319-67122-2 7

[54] Howard Shrobe, David L. Shrier, and Alex Pentland, "CHAPTER 15 Enigma: Decentralized Computation Platform with Guaranteed Privacy," 
in New Solutions for Cybersecurity, MIT Press, 2018, pp. 425-454. [Online]. Available: http://ieeexplore.ieee.org/document/8333139

[55] A. Zwitter and J. Herman, "Blockchain for Sustainable Development Goals: \#Blockchain4SDGs," Rijksuniversiteit Groningen, 2018. [Online]. Available: https://www.rug.nl/cf/events/eventsitems/blockchain4sdgs-workshop

[56] A. Chandan, V. Potdar, and M. Rosano, "How Blockchain can help in Supply Chain Sustainability," presented at the ACIS 2019, Perth Western Australia, 2019. [Online]. Available: https://aisel.aisnet.org/acis2019/101

[57] E. H. Lund, L. Jaccheri, J. Li, O. Cico, and X. Bai, "Blockchain and Sustainability: A Systematic Mapping Study," in 2019 IEEE/ACM 2nd International Workshop on Emerging Trends in Software Engineering for Blockchain (WETSEB), May 2019, pp. 16-23. doi: 10.1109/WETSEB.2019.00009.

[58] R. Chitchyan and C. Bird, "Theory as a Source of Software Requirements," in 2020 IEEE 28th International Requirements Engineering Conference (RE), Sep. 2020, pp. 227-237. doi: 10.1109/RE48521.2020.00033.

[59] D. J. Wilkins, R. Chitchyan, and M. Levine, "Peer-to-Peer Energy Markets: Understanding the Values of Collective and Community Trading," in Proceedings of the 2020 CHI Conference on Human Factors in Computing Systems, New York, NY, USA: Association for Computing Machinery, 2020, pp. 1-14. [Online]. Available: https://doi.org/10.1145/3313831.3376135

[60] L. Hughes, Y. K. Dwivedi, S. K. Misra, N. P. Rana, V. Raghavan, and V. Akella, "Blockchain research, practice and policy: Applications, benefits, limitations, emerging research themes and research agenda," Int. J. Inf. Manag., vol. 49, pp. 114-129, Dec. 2019, doi: 10.1016/j.ijinfomgt.2019.02.005.

[61] R. Medaglia and J. Damsgaard, "Blockchain and the United Nations Sustainable Development Goals: Towards an Agenda for IS Research," in PACIS 2020 Proceedings, Dubai, UAE, 2020, p. 11. [Online]. Available: https://aisel.aisnet.org/pacis2020/36

[62] Y. Tang, J. Xiong, R. Becerril-Arreola, and L. Iyer, "Ethics of blockchain," Inf. Technol. People, vol. 33, no. 2, pp. 602-632, Jan. 2020, doi: 10.1108/ITP-10-2018-0491.

[63] B. Rodrigues, T. Bocek, and B. Stiller, "Chapter Six - The Use of Blockchains: Application-Driven Analysis of Applicability," in Advances in Computers, vol. 111, P. Raj and G. C. Deka, Eds. Elsevier, 2018, pp. 163-198. doi: 10.1016/bs.adcom.2018.03.011.

[64] M. E. Peck, "Blockchain world - Do you need a blockchain? This chart will tell you if the technology can solve your problem," IEEE Spectr., vol. 54, no. 10, pp. 38-60, Oct. 2017, doi: 10.1109/MSPEC.2017.8048838.

[65] S. K. Lo, X. Xu, Y. K. Chiam, and Q. Lu, "Evaluating Suitability of Applying Blockchain," in 2017 22nd International Conference on Engineering of Complex Computer Systems (ICECCS), Nov. 2017, pp. 158-161. doi: 10.1109/ICECCS.2017.26.

[66] C. Mulligan, J. Z. Scott, S. Warren, and J. Rangaswami, "Blockchain Beyond the Hype: A Practical Framework for Business Leaders," World Economic Forum, White paper, 2018. [Online]. Available: http://www3.weforum.org/docs/48423_Whether_Blockchain_WP.pdf

[67] M. Jaatun, P. Haro, and C. Froystad, "Five Things You Should Not Use Blockchain For," in 2020 IEEE Cloud Summit, Los Alamitos, CA, USA, Oct. 2020, pp. 167-169. doi: 10.1109/IEEECloudSummit48914.2020.00032.

[68] Innovation Norway. The online SDG Explorer. https://www.theexplorer.no/goals (accessed October 7, 2021). 